\title{
Mitochondrial Oxidative Stress in Temporal Lobe Epilepsy
}

\author{
Simon Waldbaum and Manisha Patel ${ }^{*}$ \\ Department of Pharmaceutical Sciences University of Colorado Denver School of Pharmacy \\ Aurora, CO 80045 U.S.A.
}

\section{Abstract}

Mitochondrial oxidative stress and dysfunction are contributing factors to various neurological disorders. Recently, there has been increasing evidence supporting the association between mitochondrial oxidative stress and epilepsy. Although certain inherited epilepsies are associated with mitochondrial dysfunction, little is known about its role in acquired epilepsies such as temporal lobe epilepsy. Mitochondrial oxidative stress and dysfunction are emerging as key factors that not only result from seizures, but may also contribute to epileptogenesis. The occurrence of epilepsy increases with age, and mitochondrial oxidative stress is a leading mechanism of aging and age-related degenerative disease, suggesting a further involvement of mitochondrial dysfunction in seizure generation. Mitochondria have critical cellular functions that effect neuronal excitability including production of adenosine triphosphate (ATP), fatty acid oxidation, control of apoptosis and necrosis, regulation of amino acid cycling, neurotransmitter biosynthesis, and regulation of cytosolic $\mathrm{Ca}^{2+}$ homeostasis. Mitochondria are the primary site of reactive oxygen species (ROS) production making them uniquely vulnerable to oxidative stress and damage which can further affect cellular macromolecule function, the ability of the electron transport chain to produce ATP, antioxidant defenses, mitochondrial DNA stability, and synaptic glutamate homeostasis. Oxidative damage to one or more of these cellular targets may affect neuronal excitability and increase seizure susceptibility.

The specific targeting of mitochondrial oxidative stress, dysfunction, and bioenergetics with pharmacological and non-pharmacological treatments may be a novel avenue for attenuating epileptogenesis and seizure initiation.

\section{Keywords}

oxidative damage; seizure; epileptogenesis; hyperexcitability; temporal lobe epilepsy

\subsection{Introduction}

Epilepsy is a recent addition to the neurological disorders in which mitochondrial oxidative stress and dysfunction have been suggested to be contributing factors. While a small percentage of inherited epilepsies are associated with mitochondrial dysfunction, less is known about its role in acquired epilepsies such as temporal lobe epilepsy (TLE). TLE's are a group of neurological disorders in which humans and animals experience recurrent

\footnotetext{
(C) 2009 Elsevier B.V. All rights reserved.

* Correspondence to: Department of Pharmaceutical Sciences University of Colorado Denver School of Pharmacy 12700 East $19^{\text {th }}$ Avenue P-15 C238 Aurora, CO 80045 U.S.A. manisha.patel@ ucdenver.edu (p) (303) 724-3604 (f) (303) 724-7266 .

Publisher's Disclaimer: This is a PDF file of an unedited manuscript that has been accepted for publication. As a service to our customers we are providing this early version of the manuscript. The manuscript will undergo copyediting, typesetting, and review of the resulting proof before it is published in its final citable form. Please note that during the production process errors may be discovered which could affect the content, and all legal disclaimers that apply to the journal pertain.
} 
epileptic seizures arising from one or both temporal lobes of the brain. Two main types of TLE are generally recognized, mesial temporal lobe epilepsy which arises in the hippocampus, parahippocampal gyrus and amygdala, and lateral temporal lobe epilepsy which arises in the neocortex. Initial trauma associated with TLE induces complex molecular, biochemical, physiological, and structural changes in the brain that contribute to epileptogenesis and the subsequent onset of spontaneous and recurrent seizures.

Mitochondrial oxidative stress and dysfunction are emerging as key factors that not only result from seizures, but may also contribute to epileptogenesis. Precedence for the role of mitochondrial dysfunction in epilepsy comes from the knowledge that epilepsy frequently occurs with inherited mitochondrial disorders such as myoclonic epilepsy with ragged red fibers (MERRF) and those associated with childhood encephalopathies. A role of mitochondrial oxidative stress in lowering seizure threshold comes from studies in mice partially deficient in a critical mitochondrial antioxidant (Sod2-/+) that have age-dependent spontaneous seizures. The occurrence of epilepsy in humans also increases with age, and mitochondrial oxidative stress is a leading mechanism of aging and age-related degenerative disease, suggesting a further involvement of mitochondrial dysfunction in seizure generation. Mitochondria have critical cellular functions that effect neuronal excitability including production of adenosine triphosphate (ATP), fatty acid oxidation, control of apoptosis and necrosis, regulation of amino acid cycling, neurotransmitter biosynthesis, and regulation of cytosolic $\mathrm{Ca}^{2+}$ homeostasis. Mitochondria are the primary site of reactive oxygen species (ROS) production and are uniquely vulnerable to oxidative damage that may play a critical role in controlling neuronal excitability. Further, mitochondria are critically involved in excitotoxicity and programmed cell death which independently contribute to seizure-induced hippocampal cell loss. As such, the targeting of mitochondrial oxidative stress and dysfunction may be a novel avenue for the development of new drugs that are neuroprotective, able to preserve neuronal viability and function, antiepileptic, able to attenuate seizure occurrence in epileptic patients, and antiepileptogenic, able to attenuate the development of the epileptic phenotype following an insult.

This review outlines studies supporting the emerging role of mitochondrial oxidative stress and dysfunction in epilepsy with emphasis on TLE. Evidence from a variety of animal models of TLE is discussed including the use of the chemoconvulsants kainic acid (KA), a glutamatergic agonist, and pilocarpine, a muscarinic acetylcholine agonist. Other animal models discussed include the use of pentylenetetrazole (PTZ) and electrical kindling. Evidence for the production and consequences of acute and chronic mitochondrial oxidative stress and dysfunction in various animal models of TLE are discussed with damage to proteins, lipids, mitochondrial DNA (mtDNA), and antioxidant defenses being considered. Mitochondrial oxidative stress and dysfunction as causes and/or consequences of epileptic seizures are given attention. Transgenic mice models of mitochondrial oxidative stress are discussed in relation to seizure production. The role of synaptic glutamate homeostasis in relation to glutamine synthetase and glial glutamate transporters are considered due to their known sensitivity to oxidative damage and contribution in controlling neuronal excitability. Lastly, the targeting of mitochondrial bioenergetics with pharmacological and nonpharmacological treatments as a means of attenuating epileptogenesis and seizure initiation is discussed.

\subsection{Mitochondrial structure and functions}

\subsubsection{Mitochondrial structure}

Mitochondria are double-membrane bound intracellular organelles containing their own unique genome responsible for critical cellular functions in nearly all eukaryotic cells. The outer and inner mitochondrial membranes separate the matrix and intermembrane space (Koehler, 2004). The porin containing outer membrane is permeable to molecules $<5-6 \mathrm{kDa}$ 
(Benz, 1994), and larger proteins must have a specific signaling sequence to be transported across the membrane. The inner membrane is highly impermeable to ions and solutes, contains specific ion channels and transport systems, and is compartmentalized into numerous cristae which expand its surface area. The inner membrane has a high protein to phospholipid ratio and contains the enzymes involved in the electron transport chain (ETC) and ATP synthesis which create the mitochondrial membrane potential. mtDNA is a unique and independent functional genome inherited maternally (Leonard and Schapira, 2000) and is made up of a $16.5 \mathrm{kB}$ circular, double-stranded DNA whose 37 genes encode 13 polypeptides of the ETC, 22 tRNAs, and 2 rRNAs. However, most mitochondrial gene products are encoded by nuclear DNA (nDNA) and imported (DiMauro and Schon, 2003). Due to their high degree of mobility along cytoskeletal transport mechanisms, neuronal mitochondria can be positioned based on specific metabolic demands (Hollenbeck and Saxton, 2005) which increase during seizure activity.

\subsubsection{Mitochondrial functions}

The primary function of mitochondria is the production of ATP to be used as cellular energy via the metabolic processes of the tricarboxylic acid cycle (TCA) and the ETC. The mitochondria are responsible for the majority of the cells ATP supply via oxidative phosphorylation located on its inner membrane. The majority of ATP produced by the mitochondria is utilized to maintain the $\mathrm{Na}^{+} / \mathrm{K}^{+}$ATPase which in turn maintains neuronal membrane potential and excitability. The TCA cycle's primary role is the production of the coenzymes NADH and FADH which carry electrons to the ETC. Although the ETC efficiently shuttles electrons to $\mathrm{O}_{2}$ to phosphorylate ADP in the production of ATP, some electrons can "leak" out and react with molecular oxygen generating superoxide radical $\left(\mathrm{O}^{-}{ }_{2}\right)$, particularly at complex I and III (St-Pierre et al., 2002; Muller et al., 2004) (Fig 1). Also, on the outer mitochondrial membrane the action of monoamine oxidases are associated with a two electron reduction of $\mathrm{O}_{2}$ to hydrogen peroxide $\left(\mathrm{H}_{2} \mathrm{O}_{2}\right)$ (Hauptmann et al., 1996). The steady state concentration of $\mathrm{O}_{2} \cdot{ }^{-}$in the mitochondrial matrix, based on the rate of $\mathrm{O}_{2}{ }^{-}$production by the ETC and concentration of the mitochondrial antioxidant manganese superoxide dismutase (MnSOD), is estimated to be $\sim 10^{-10} \mathrm{M}$ (Tyler, 1975; Fridovich, 1978; Imlay and Fridovich, 1991; Gardner and Fridovich, 1992; Fridovich, 1995). As such, mitochondria are the major source of intracellular ROS with estimates ranging from $0.1-4 \%$ of oxygen consumption going to $\mathrm{O}_{2}{ }^{-}$generation in the mitochondria (Boveris, 1984).

In addition to ATP and ROS production, mitochondria play a critical role in other cellular processes illustrated in Figure 1. Mitochondria sequester free intracellular $\mathrm{Ca}^{2+}$ through several transport systems and are important to $\mathrm{Ca}^{2+}$ homeostasis (Nicholls, 1985; Duchen, 2000). $\mathrm{Ca}^{2+}$ can play a regulatory role by influencing mitochondrial processes such as the consumption of $\mathrm{H}_{2} \mathrm{O}_{2}$ and enzyme activity i.e. pyruvate dehydrogenase and metabolic rate. Alternatively, the mitochondrial permeability transition pore (MPT) can be stimulated to open by excessive concentrations of $\mathrm{Ca}^{2+}$, and can also extrude $\mathrm{Ca}^{2+}$ (Zoratti and Szabo, 1995). Mitochondria play an important role in the mediation of cell death via pro-apoptotic factors (Schapira, 2002) which utilize the transition pore (Mancini et al., 1998; Susin et al., 1999). Other vital mitochondrial functions include synthesis of lipids, metabolites and amino acids including neurotransmitters, fatty acid oxidation, and control of necrotic cell death. Each of these vital inter-related mitochondrial functions is crucial for normal brain function, and a defect in one or more of these may be a likely contributor to neuronal excitability and epileptogenesis. 


\subsection{Mitochondrial oxidative stress and epileptic seizures}

\subsubsection{Mitochondrial oxidative stress}

Oxidative stress results from an imbalance in oxidant and antioxidant homeostasis in favor of the production of ROS. A free radical is defined as an atom or group of atoms possessing one or more unpaired electron in their orbital, allowing them a strong propensity to react with other molecules giving or taking an electron to complete their orbital (Castagne et al., 1999; Halliwell and Gutteridge, 2007). ROS production is a normal part of aerobic respiration, and continuously occurs as electrons escape complex I and III of the mitochondrial ETC (St-Pierre et al., 2002; Muller et al., 2004). The production of $\mathrm{O}_{2} \cdot{ }^{-}$and $\mathrm{H}_{2} \mathrm{O}_{2}$ by the ETC in close proximity to $\mathrm{Cu}^{2+}$ and $\mathrm{Fe}^{2+}$ in mitochondrial membranes can lead to the generation of the highly reactive hydroxyl radical $\left(\mathrm{OH}^{-}\right)$through the Fenton reaction which readily oxidizes proteins, lipids, and DNA (Fig. 1). ROS are transient, unstable, and largely localized to cellular compartments, making their direct measurement difficult. As a result, the role of free radicals in pathologic conditions has been inferred from the measurement of indirect markers of oxidative stress such as lipid and protein oxidation and the activities of free radical scavenging enzymes (Bruce and Baudry, 1995; Patel, 2004). The brain is particularly vulnerable to oxidative stress-induced damage due to a large quantity of mitochondria, a high degree of oxidizable lipids and metals, a high oxygen consumption, and less antioxidant capacity than other tissues making oxidative stress a likely contributor to neurological disorders such as the epilepsies.

\subsubsection{Mitochondrial oxidative stress: cause or consequence of epileptic seizures}

There is mounting evidence for oxidative stress as an important contributing factor to seizure associated neuronal damage and death. ROS are integral to processes such as excitotoxicity and apoptosis that contribute to seizure-induced brain damage. A contributing role for ROS in seizure-induced neuronal death is supported in part by the observation that prolonged seizures result in increased oxidation of cellular macromolecules (Bruce and Baudry, 1995), while various compounds with antioxidant properties prevent excitotoxicity in vitro (Monyer et al., 1990; Lafon-Cazal et al., 1993; Puttfarcken et al., 1993; Patel, 1996) and in vivo (Schulz et al., 1995; MacGregor et al., 1996). Experimental seizures have been shown to result in impaired mitochondrial $\mathrm{Ca}^{2+}$ sequestering, excessive ROS production, and increased nitric oxide (NO) and peroxynitrite $\left(\mathrm{ONOO}^{-}\right)$generation after prolonged seizures at timepoints preceding neuronal death in susceptible brain regions (Griffiths et al., 1984; Cheng and Sun, 1994; Bruce and Baudry, 1995; Kunz et al., 1999; Liang et al., 2000; Frantseva et al., 2000a; Milatovic et al., 2002). However, a variety of animal model studies provide evidence for a lack of oxidative damage to cellular macromolecules following seizures. For example, an initial increase in ETC complex activity and subunit expression has been demonstrated in the KA (Milatovic et al., 2001) and kindling models (Sleven et al., 2006a), and no alterations to ETC complexes or mtDNA have been reported at chronic timepoints following pilocarpine-induced SE (Nasseh et al., 2006). It should be noted that although it is often difficult to separate the effects of chemoconvulsant agents used in animal models of status epilepticus (SE) from the seizure events themselves. For example, intracortical application of iron has been used as a model of post-traumatic epilepsy (Kucukkaya et al., 1998), but also stimulates free radicals such as $\mathrm{OH}^{-}{ }^{-}$(Gutteridge, 1992). Following 3-mercaptoproprionic acid-induced seizures in rats, lipid peroxidation has been shown to increase in as little as 3-6 min post-onset in susceptible brain regions. In the PTZ model, free radical production has been reported immediately following seizures (Rauca et al., 1999). (See Devi et al. (2008) for a list of the modulation to oxidant/antioxidant balance in rodents following experimental seizures (Devi et al., 2008)). Nonetheless, evidence from various animal models suggests that free radical production increases after brief and prolonged seizure episodes. 
While many studies have investigated acute consequences of SE on cellular constituents, less is known about the role of oxidative stress and mitochondrial dysfunction in chronic epilepsy. Determining the role of mitochondrial dysfunction in chronic epilepsy is complicated by the difficulty in distinguishing mitochondrial oxidative stress as a cause or consequence of seizures. Nonetheless, several key studies support the idea that mitochondrial oxidative stress and dysfunction can cause epileptic seizures. For example, seizure activity can be induced by paradigms which can increase the mitochondrial free radical load, such as increased oxygen levels (Freeman et al., 1982; Yusa et al., 1987; Jenkinson, 1989; Komadina et al., 1991; Elayan et al., 2000) age-related neuronal disorders such as stroke (Velioglu et al., 2001), and brief periods of neonatal hypoxia-reoxygenation (Jensen et al., 1991; Jensen et al., 1992). Additionally, synaptic N-methyl-D-aspartate (NMDA) receptor activation resulting in increased mitochondrial $\mathrm{O}_{2} \cdot{ }^{-}$production is a necessary component of seizures (Dugan et al., 1995; Li et al., 2001). One month following pilocarpine-induced SE, mitochondrial dysfunction is evident by decreased ETC complex I and IV activity, increased complex II activity, and lowered mitochondrial membrane potential measured by rhodamine 123 fluorescence in the hippocampal CA1 and CA3 regions (Kudin et al., 2002). These abnormalities were attributed by the authors to chronic oxidative stress that decreased mtDNA copy number resulting in down regulation of ETC enzymes that they encoded. The acute increase in mitochondrial oxidative stress following SE may over time result in oxidative damage to mtDNA, as suggested by increased levels of the oxidized guanine adduct, 8-hydroxy-2-deoxyguanosine (8-OHdG), and decreased expression of mitochondrially encoded proteins required for proper ETC function. Seizureinduced accumulation of oxidative mtDNA lesions and resultant somatic mtDNA mutations could, over time, render the brain more susceptible to subsequent epileptic seizures. Further, ultrastructural damage to mitochondria has been observed in the hippocampus of chemoconvulsant-treated epileptic rats (Chuang et al., 2004). The link between mitochondrial dysfunction and epilepsy is further supported by the finding that certain patients with TLE show mitochondrial complex I deficiency in the seizure foci (Kunz et al., 2000). Thus, recent evidence supports the role of mitochondrial oxidative stress not merely as a consequence of seizures, but an active contributor to seizures and epileptogenesis.

\subsection{Seizure-induced oxidative damage to cellular macromolecules: relationship with neuronal excitability}

Recent evidence has suggested that oxidative stress affecting a number of metabolic processes may contribute to neuronal excitability, and potentially be an active mechanism contributing to epilepsy. Mechanisms that may be active during the "latent period" as chronic epilepsy develops include a reduction in mitochondrial redox status leading to irreversible oxidation, mtDNA damage, the failure of mitochondrial repair, and decreased oxidative phosphorylation and ATP production by mitochondria. While decreased ATP production and in turn ATP-dependent $\mathrm{Na}^{+} / \mathrm{K}^{+}$ATPase is sufficient to increase neuronal excitability (Jamme et al., 1995; Fighera et al., 2006), decreased expression and/or function of astrocytic glutamate transporters and glutamate synthetase due to oxidative stress and redox modulation of ion channels may be additional mechanisms of increased neuronal excitability.

\subsubsection{Oxidative damage to proteins}

Proteins exposed to ROS exhibit altered primary, secondary, and tertiary structures, undergo spontaneous fragmentation and manifest increased proteolytic susceptibility. The amino acid side chains of proteins are particularly susceptible to oxidation, such as irreversible damage to the ring cleavage in histidine or tryptophan, the reversible oxidation of thiol groups, and methionine oxidized to the sulfoxide and then further to the sulfone which is associated with 
loss of function. Although disulfide bonds are a reversible process, these changes may significantly alter proper function changed by thiol/disulfide status. Oxidative damage to proteins can be estimated based on carbonyl content and has been found to be high in specific brain regions and to be elevated during aging and neurodegenerative disorders (Forster et al., 1996; Floor and Wetzel, 1998). In the KA model of epilepsy, an early increase in carbonyl content in the piriform cortex and hippocampus at $8 \mathrm{hr}$ post-treatment has been reported which returned to control levels by $48 \mathrm{~h}$ (Bruce and Baudry, 1995). This early increase in protein oxidation in adult animals suggests free radical involvement in the initial phases of KA-induced pathology and fits with the hypothesis that prolonged activation of glutamate receptors leads to an increase in ROS. Four hours post-KA treatment, protein carbonyl levels have been shown to be elevated in the hippocampus, cortex, basal ganglia, and cerebellum with levels persisting up to $24 \mathrm{~h}$ in the hippocampus and cerebellum (Gluck et al., 2000). Elevations of oxidative stress-induced damage to proteins lasting $24 \mathrm{~h}$ suggests ongoing KA oxidative damage or repair mechanisms for removal of oxidized proteins requiring more than $24 \mathrm{~h}$ to be activated. Variation in the localization of oxidative damage suggests the cortex may have different mechanisms than the cerebellum or hippocampus for free radical scavenging or increased repair.

Mitochondrial aconitase is a TCA cycle enzyme that contains a labile iron motif in its ironsulfur (Fe-S) center that is susceptible to oxidative damage by $\mathrm{O}_{2} \cdot{ }^{-}$and related species (Fig. 1). The measurement of endogenous aconitase activity can serve both as an index of steady state $\mathrm{O}_{2} \cdot{ }^{-}$levels and evidence of oxidative damage to proteins (Gardner and Fridovich, 1992; Fridovich, 1997). Inactivation of aconitase normalized to fumarase or citrate synthetase has been used to determine oxidative damage to mitochondrial proteins in animal models of SE and human TLE. KA-induced seizures inactivate mitochondrial aconitase but not fumarase, with maximal inactivation occurring $16 \mathrm{hrs}$ post-treatment, several hours after SE and preceding neuronal death of susceptible hippocampal neurons (Liang et al., 2000). Inactivation of mitochondrial aconitase at times following the onset of behavioral seizures suggests that mitochondrial $\mathrm{O}_{2}{ }^{-}$production may occur as a consequence of prolonged seizure activity. Mice that are partially deficient in MnSOD (SOD2) $\left(\operatorname{Sod} 2^{-/+}\right.$) show evidence of exacerbated KA-induced mitochondrial aconitase inactivation and hippocampal neuronal loss (Liang and Patel, 2004), while overexpressing SOD2 mice show both are attenuated. Manganese (III) tetrakis (4-benzoic acid) porphyrin (MnTBAP), a broad spectrum antioxidant, protects rats against seizure-induced mitochondrial aconitase inactivation and hippocampal damage without decreasing behavioral seizure intensity or frequency (Liang and Patel, 2004). Pilocarpine-induced SE also showed a decrease in aconitase and alpha ketoglutarate dehydrogenase $16-44 \mathrm{~h}$ post-SE, which returned to normal by $8 \mathrm{~d}$ in the hippocampus (Cock et al., 2002). Finally, aconitase activity is decreased in the CA3 region of human cases of TLE (Vielhaber et al., 2008). One consequence of oxidative inactivation of aconitase is the release of iron and generation of $\mathrm{H}_{2} \mathrm{O}_{2}$ which can form $\mathrm{OH}^{-}$ and thereby result in further oxidative damage. As such, SE-induced changes in hippocampal mitochondrial iron coinciding with inactivation of mitochondrial aconitase have recently been demonstrated (Liang et al., 2008).

\subsubsection{Oxidative damage to the mitochondrial electron transport chain}

Seizure-induced ROS production could alter critical proteins involved in controlling neuronal excitability making them more susceptible to degradation by intracellular proteolytic systems and thereby increasing seizure susceptibility. The mitochondrial ETC is critical to phosphorylation processes, regulation of membrane permeability, neurotransmitter biosynthesis, exocytosis, and the primary source of cellular ATP involved in maintaining ion pumps such as the $\mathrm{Na}^{+} / \mathrm{K}^{+}$ATPase which contribute to neuronal excitability. When ETC enzymes are not functioning properly, as may occur in TLE, the levels of mitochondrial 
ROS increases culminating in oxidative damage (Bandy and Davison, 1990). It has been demonstrated that the mitochondrial ETC can be differentially inactivated by ROS whereby $\mathrm{OH}^{-}$alone and in combination with $\mathrm{O}_{2}$ rapidly inactivates complex I and II, $\mathrm{O}_{2}$ alone inactivates complex I, and $\mathrm{H}_{2} \mathrm{O}_{2}$ partially inactivates complex I (Zhang et al., 1990). Complex IV was largely resistant to oxidative inactivation in these studies with the exception of partial inactivation by $\mathrm{H}_{2} \mathrm{O}_{2}$. Complex I of the mitochondrial ETC is a major producer of $\mathrm{O}_{2}{ }^{-}$, mitochondrial ROS, redox signaling (Cadenas and Davies, 2000; Taylor et al., 2003), and has been demonstrated to be more susceptible to oxidative stress and glutathionylation compared to other ETC complexes (Taylor et al., 2003). Additionally, it has been implicated in NO physiology, induction of MPT opening, and regulation of apoptosis (Moncada and Erusalimsky, 2002). Impaired mitochondrial ETC function as a result of ROS may lead to $\mathrm{Ca}^{2+}$-dependent depolarization of the mitochondrial membrane potential resulting in incomplete oxygen consumption, reduced production of ATP, and overproduction of ROS (Cadenas and Davies, 2000; Nicholls and Ward, 2000; Heinemann et al., 2002; Patel, 2002). As inhibition of the ETC produces excess ROS, which are direct inhibitors of the ETC and TCA enzymes, a vicious cycle can result leading to oxidative cell damage (Cadenas and Davies, 2000; Patel, 2004).

Evidence in support of seizure-induced oxidative damage to mitochondrial ETC complexes has been somewhat contradictory. KA-induced seizures have been shown to initially increase complex IV activity, the terminal enzyme complex of the mitochondrial ETC, and complex IV subunit mRNA $1 \mathrm{~h}$ post-SE in the amygdala, hippocampus, and frontal cortex which decreased by $3 \mathrm{~d}$ in the amygdala and hippocampus (Milatovic et al., 2001). In studies where KA was administered directly into CA3 producing seizures and ictal electroencephalogram (EEG) activity, depressed activity of nicotinamide adenine dinucleotide cytochrome $\mathrm{c}$ reductase (NCCR), a marker for complex I and III, was observed at 180 min post-injection in all hippocampal subfields while succinate cytochrome c reductase, a marker for complex II and III, and complex IV remained unaltered (Chuang et al., 2004). These changes were accompanied by swelling of mitochondrial spaces and membrane disruption, suggesting that complex I enzyme dysfunction and mitochondrial ultrastructural damage in the hippocampus were associated with prolonged seizures. However, it should be noted that the excitotoxic effects of direct injection of KA are difficult to discern from the seizures themselves. Results from the pilocarpine model have demonstrated decreased activity of complex I and IV, increased flux control of complex I and decreased respiration rates in CA 1 and CA $330 \mathrm{~d}$ post-treatment, with no changes detected in the dentate gyrus or parahippocampal gyrus (Kudin et al., 2002). These results suggest that seizure activity per se downregulates expression of mitochondrial encoded enzymes of oxidative phosphorylation. Forty five days post-pilocarpine-induced SE, mitochondrial encoded complex IV subunit III decreased while nuclear encoded subunit IV remained unchanged along with nuclear encoded complex II in the hippocampus (Gao et al., 2007). These results suggest that mitochondria are particularly susceptible to seizureinduced oxidative damage. Alternatively, no altered expression of complex I or complex IV activity has been reported $60 \mathrm{~d}$ post-pilocarpine treatment (Nasseh et al., 2006). These differences, however, may be due to the fact that the Kudin et al. (2002) study used hippocampal regions for their studies while the Nasseh et al. (2006) study used whole hippocampi. Evidence from the kindling model has shown a transient decrease in complex I activity at $16 \mathrm{~h}$ in CA3 and an increase in complex II and III activity, which may be an attempt to upregulate mitochondrial ETC activity and compensate for a deficiency in complex I (Sleven et al., 2006a). Another study reports increased activity of complex I and increased expression of complex IV subunits in epilepsy prone EL mice (Yamada and Nakano, 1999). Disruption in the ETC and/or one or more of its ATP-dependent processes, as reported by a number of studies, could have significant effects on neuronal excitability that may contribute to seizure activity. 


\subsubsection{Seizure-induced damage to glutamate transporters}

Neuronal and glial transporters are responsible for preventing synaptic glutamate levels from achieving neurotoxic levels (Rothstein et al., 1994a; Rothstein et al., 1996) and have been implicated in hyperexcitability and neuronal death. Glial glutamate transporters, GLAST (EAAT-1) and GLT-1 (EAAT-2), and three neuronal glutamate transporters, EAAT-3, EAAT-4, and EAAT-5, are known to be located in the plasma membrane (Kanai and Hediger, 1992; Pines et al., 1992; Storck et al., 1992; Fairman et al., 1995; Arriza et al., 1997). Although both neurons and glia contain glutamate transporters, it is believed that the majority of glutamate uptake activity is mediated by glial transporters, and in particular GLT-1, whose expression is most abundant in the hippocampus and cerebral cortex (Danbolt et al., 1990; Haugeto et al., 1996; Danbolt, 2001). GLT-1 has been demonstrated to be regulated by extracellular changes in ATP through activation of the extracellular signalregulated protein kinase (ERK) pathway in hippocampal slices (Frizzo et al., 2007).

Glutamate transporters are known to be highly sensitive to oxidative damage resulting in reduced uptake function (Trotti et al., 1998). These alterations may contribute to an increase in neurotoxic extracellular glutamate levels and increased neuronal excitability producing significant pathological consequences.

Evidence from animal studies suggests that increasing the time neurotransmitter remains in the synaptic cleft, as in the case of altered glutamate transporters, affects postsynaptic ionotropic synaptic currents (Otis et al., 1996) and may affect hippocampal neurotransmission and promote seizures. The use of the glutamate transport inhibitor, threo$\beta$-benzyloxyaspartate, prolongs epileptiform activity (Shimamoto et al., 1998) and causes alternating periods of bursting activity and hypoactivity in young rats (Milh et al., 2007). Genetically altered mice lacking GLT-1 develop spontaneous seizures (Tanaka et al., 1997) and GLAST knockout mice display increased susceptibility to seizures (Ueda et al., 2002). Levels of EAAC-1 expression have been reported to decrease following kindling (Ghijsen et al., 1999) but increase following KA-induced SE and kindling in other studies (Miller et al., 1997; Gorter et al., 2002). An increase in GLAST mRNA and GLT-1 expression has also been reported (Nonaka et al., 1998) along with a decrease in EAAT-3 mRNA (Akbar et al., 1998). Further, decreased expression of GLT-1 and GLAST has been observed in the cortex of rats with genetic absence epilepsy (Dutuit et al., 2002) and in the hippocampus of epileptic EL mice (Ingram et al., 2001). Additionally, the expression of GLT-1, GLAST, and EAAC-1, were reported to decrease in epileptic Sod $2^{-/+}$and Sod2 $2^{+/+}$mice at increasing ages (Liang and Patel, 2004). The decrease in hippocampal GLT-1 and GLAST in Sod2 ${ }^{-/+}$mice coincided with decreased aconitase activity as well as increased mitochondrial oxidative stress and seizure susceptibility which may explain the age-related vulnerability of a subset of these mice to epileptic seizures. The latter observations suggest that mitochondrial oxidative stress and resultant dysfunction may be sufficient to increase seizure susceptibility via alterations to glial glutamate transporters.

Alterations in the glutamatergic system have been suggested to play a role in the development of epileptogenesis in humans. Hippocampal sclerosis has been correlated with reduced hippocampal volume, elevated extracellular glutamate levels (Ronne-Engstrom et al., 1992; During and Spencer, 1993; Cavus et al., 2005), and a down regulation of glutamate transporters has been implicated in impaired glutamate uptake capacity (Meldrum et al., 1999). The levels of GLAST protein was reportedly lower in samples from epileptic patients than controls (Tessler et al., 1999) and a decrease in GLT-1 expression was reported in the hippocampus of sclerotic tissue obtained from resected TLE patients (Mathern et al., 1999). However, immunocytochemical studies in patients with and without hippocampal sclerosis found no significant differences or an increase in transporter expression (Proper et al., 2002; Bjornsen et al., 2007), but have suggested excessive glutamate release or modulation of transporter function as a potential contributing factor to seizure susceptibility. 
Seizure associated neuronal loss may decrease glial glutamate transporters, and a decrease in glial glutamate transporter function may increase extracellular glutamate levels and lead to further neuronal loss. It should be noted, however, that some alterations in transporters such as splice variants (Hoogland et al., 2004) may not be distinguishable by antibodies used in immunoreactive studies.

\subsubsection{Seizure-induced alterations of glutamine synthetase}

Extracellular glutamate is normally taken up by astroglial glutamate transporters and rapidly converted to the non-excitotoxic amino acid glutamine by glutamine synthetase (GS) in a process requiring ATP and metal ions for catalysis (Eisenberg et al., 2000). Glutamine is subsequently transported back into neurons where it can be reconverted back to glutamate, a process known as the glutamate/glutamine cycle (Hertz, 1979). A decrease in the rate of this cycle has been reported in the hippocampus of TLE patients using in vivo MR spectroscopy (Petroff et al., 2002). Results of GS expression from surgically resected TLE patients have been contradictory. Decreased levels of GS have been reported following hippocampal sclerosis (Petroff et al., 2002; Eid et al., 2004; van der Hel et al., 2005) and an increase in glutamine and glutamate in the thalamus in epileptic patients has been reported (Helms et al., 2006). However, another study failed to demonstrate alterations in GS expression in the epileptic cortex (Steffens et al., 2005).

Studies from epileptic animals have been more consistent in their results regarding levels of GS. Decreased GS expression (Laming et al., 1989; Dutuit et al., 2000), induction of seizures by inhibiting GS activity (Folbergrova et al., 1969), seizure production in rats following systemic administration of the competitive antagonist methionine sulphoximine (Szegedy et al., 1978), and a reduction in brain GS activity after antiepileptic drug therapy (Fraser et al., 1999) have all been reported. In the KA model, a transient increase in GS expression was reported during the "latent period" which was reduced during the transition to the chronic phase of epilepsy suggesting a decreased capacity for glutamate metabolism as spontaneous and recurrent seizures became evident (Hammer et al., 2008). Also, an acute decrease in GS activity has been reported $24 \mathrm{~h}$ following intrahippocampal KA injections (Waniewski and McFarland, 1990) and a decrease in GS immunoreactivity up to $3 \mathrm{~d}$ following i.v. injection of KA followed by an increase in GS immunoreactivity between 5-68 days (Ong et al., 1996). Inhibition of GS by methionine sulphoximine in organotypical hippocampal cultures has been demonstrated to cause a depletion of glutamine and the accumulation of glutamate in astrocytes (Laake et al., 1995). In an animal model of hippocampal GS deficiency, the majority of rats demonstrate spontaneous and recurrent seizures and a subset exhibit neuropathological features similar to TLE patients suggesting that hippocampal GS deficiency causes recurrent seizures and restoring their levels may be a novel approach to treating epilepsy (Eid et al., 2008).

It is known that GS is oxidized under conditions of oxidative stress and that GS activity is particularly sensitive to reactive nitrogen and oxygen species (Oliver et al., 1990; Smith et al., 1991; Butterfield et al., 1997). For example, it has been demonstrated that nitration of GS causes a loss of its activity without affecting its antibody detectability (Gorg et al., 2005) and that high concentrations of nitric oxide synthase are present in the piriform and entorhinal cortex (Bidmon et al., 1997). NO reversibly inhibits GS activity suggesting that a covalent modification such as nitrosylation or nitration causes its inhibition (Kosenko et al., 2003). Nitric oxide synthase (NOS) inhibition results in an increase in GS activity in cultured astrocytes and in the rat brain (Minana et al., 1997; Kosenko et al., 2003; Rose and Felipo, 2005) and reportedly protected GS from NMDA-induced inactivation in brain slices (McBean et al., 1995). The generation of $\mathrm{ONOO}^{-}$from the reaction of $\mathrm{NO}$ with $\mathrm{O}_{2} \cdot{ }^{-}$may further nitrate protein tyrosine residues (Beckman and Koppenol, 1996) and has been shown to inactivate mammalian GS in vitro (Gorg et al., 2007). In PTZ-induced seizures, tyrosine 
nitration and partial inhibition of GS has been reported (Bidmon et al., 2008). Further, protein tyrosine nitration has been reported in seizures induced by hyperbaric oxygen treatment (Chavko et al., 2003). Excessive oxidative stress may irreversibly damage GS structure and predispose it to proteosome degradation (Gorg et al., 2007). It has recently been hypothesized that nitration of GS may induce a neuropathological cascade which contributes to the transformation of normal tissue to become epileptogenic (Bidmon et al., 2008).

\subsubsection{Redox modulation of ion channels}

Ion channels can be modulated by a wide variety of factors that can alter neuronal excitability. While protein phosphorylation has been well documented as a modulator of channel function, redox alterations have begun to emerge as a significant determinant of ion channel function (DiChiara and Reinhart, 1997). A variety of ligand-gated ion channels have been shown to be regulated by redox status such as nicotinic acetylcholine receptors (Xie et al., 1992; Sorenson and Gallagher, 1993; Servent et al., 1995), glycine receptors (Ruiz-

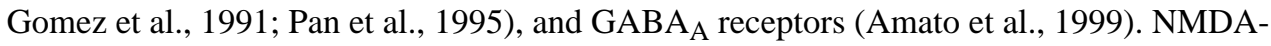
mediated responses can be substantially potentiated by reducing agents while oxidizing agents can diminish those responses (Majewska et al., 1990; Reynolds et al., 1990; Sucher et al., 1990; Traynelis and Cull-Candy, 1991) affecting excitotoxicity (Levy et al., 1990; Tauck and Ashbeck, 1990; Aizenman and Hartnett, 1992), long-term potentiation (Tauck and Ashbeck, 1990), and neurotransmitter release (Woodward and Blair, 1991). Hippocampal large-conductance $\mathrm{Ca}^{2+}$-activated $\mathrm{K}^{+}$channels $\left(\mathrm{BK}_{\mathrm{Ca}}\right)$ are responsible for action potential repolarization, generation of fast afterhyperpolarizations (Lancaster and Nicoll, 1987; Storm, 1987), and have been suggested to play an important role in regulating neuronal excitability at the resting membrane potential (Wann and Richards, 1994; Kang et al., 1996). The role of redox-induced alterations to $\mathrm{BK}_{\mathrm{Ca}}$ channels has been investigated in various cell types (Park et al., 1995; Thuringer and Findlay, 1997; Wang et al., 1997) including central nervous system neurons (Liu et al., 1999; Gong et al., 2000). In CA1 pyramidal cells from the adult rat hippocampus the activity of $\mathrm{BK}_{\mathrm{Ca}}$ channels was enhanced by intracellular exposure to the oxidizing agents 5,5'-dithio-bis(2-nitrobenzoic acid) (DNTB) and GSSG, and restored by the reducing agents dithiothreitol (DTT) and glutathione (GSH), suggesting modulation of $\mathrm{BK}_{\mathrm{Ca}}$ channel function by alterations in redox status (Gong et al., 2000). In neocortical neurons from mice, however, $\mathrm{BK}_{\mathrm{Ca}}$ channel function was unaffected by oxidation but changed by a reducing agent (Liu et al., 1999). $\mathrm{BK}_{\mathrm{Ca}}$ channels may be differentially affected by redox agents due to the sulfhydryl group of cysteine residues they contain (DiChiara and Reinhart, 1997). Changes to $\mathrm{BK}_{\mathrm{Ca}}$ channels by redox status suggests that increased levels of oxidative stress may enhance channel activity and be a contributing mechanism toward increasing neuronal excitability as occurs during epileptogenesis.

The A-type current $\left(\mathrm{I}_{\mathrm{A}}\right)$ is a fast transient $\mathrm{K}^{+}$current that plays a crucial role in the regulation of neuronal excitability based on its contribution to action potential repolarization (Storm, 1987; Riazanski et al., 2001), regulating interspike interval (Hahn et al., 2003), and increasing the latency to current injected-induced first spikes (Gustafsson et al., 1982). Atype currents are known to be modulated by second messenger cascades and phosphorylation (Martens et al., 1999). Evidence for A-type current modification by oxidation is partly based on sensitivity to oxidation demonstrated in hippocampal neurons (Muller and Bittner, 2002), oxidation-induced loss of activation for the $\mathrm{K}_{\mathrm{V}} 3.4$ and $\mathrm{K}_{\mathrm{V}} 1.4$ subunits (Ruppersberg et al., 1991), and the ability of arachidonic acid to inhibit postsynaptic $\mathrm{I}_{\mathrm{A}}$ in CA1 pyramidal neurons (Angelova and Muller, 2006) and be slowed by the addition of a water soluble Vit E derivative (Angelova and Muller, 2009). Additionally, pharmacological blockade of $\mathrm{I}_{\mathrm{A}}$ causes seizure activity (Juhng et al., 1999) and $\mathrm{I}_{\mathrm{A}}$ has been demonstrated to be regulated by cellular redox status in control and pilocarpine-treated 
epileptic rats whereby decreased GSH/GSSG caused an acceleration of recovery from inactivation which may allow neurons to reduce the cumulative inactivation of $\mathrm{I}_{\mathrm{A}}$ during high-frequency activity and serve as a protective mechanism to limit excitability (Ruschenschmidt et al., 2006). However, epileptic activity was not found to produce chronic changes in the molecular and functional properties of the somatic $\mathrm{I}_{\mathrm{A}}$ of dentate granule cells (Ruschenschmidt et al., 2006). The redox sensitivity of $\mathrm{I}_{\mathrm{A}}$ may render them particularly susceptible to modulation during seizure activity and epileptogenesis suggesting their contribution to epilepsy associated neuronal excitability.

An inactivation-resistant TTX-sensitive $\mathrm{Na}^{+}$current $\left(\mathrm{I}_{\mathrm{Na}, \mathrm{p}}\right)$ has been identified in neurons (Gilly and Armstrong, 1984; Taylor, 1993; Crill, 1996) that is thought to play a role in a pacemaking current and enhancement of rythmicity leading to repetitive action potential firing (Taylor, 1993). It has been shown that NO increases $I_{N a, p}$ which may lead to increased neuronal firing rate, neuronal excitability, disruption of normal membrane potential, and rhythmic firing of action potentials (Alonso and Llinas, 1989; Amitai, 1994; Hammarstrom and Gage, 1999). Additionally, NO deprivation by NOS inhibitors and NO scavengers caused depression of both excitatory postsynaptic currents (EPSC's) and inhibitory postsynaptic currents (IPSC's) and prevented initiation of seizure-like events in hippocampal slices from rats and mice. These results suggest that enhancement of synaptic transmission by NO under epileptic conditions may represent a positive feedback mechanism for the initiation of seizure-like events (Kovacs et al., 2009). NO may directly modulate channel protein structure by reacting with protein thiols resulting in S-nitrosylation (Stamler et al., 1992) and allowing disulfide bond formation in the channel protein (Lei et al., 1992). An increase in $\mathrm{I}_{\mathrm{Na}, \mathrm{p}}$ induced by increased oxidative stress could cause membrane depolarization, increased neuronal excitability, and firing rate associated with seizures.

\subsection{Seizure-induced oxidative damage to lipids}

Polyunsaturated fatty acids present in phospholipids of biological membranes are highly susceptible to oxidation by ROS. Unspecific oxidation of polyunsaturated fatty acids, known as lipid peroxidation, is a free radical mediated pathway and is used as an index of irreversible neuronal damage of cell membrane phospholipids suggested as a possible mechanism of epileptic activity (Dal-Pizzol et al., 2000). Lipid peroxidation is partly caused by hydrogen abstraction from polyunsaturated fatty acids by $\mathrm{OH}^{-}{ }^{-}$transformed from $\mathrm{H}_{2} \mathrm{O}_{2}$ and $\mathrm{O}_{2} \cdot{ }^{-}$by the catalytic action of transition metals (Halliwell and Gutteridge, 1986; Coyle and Puttfarcken, 1993). The brain is particularly susceptible to injury by lipid peroxidation products and is highly sensitive to oxidative stress. Due to a high content of polyunsaturated phospholipids and a major site of ROS production, the mitochondria are also particularly sensitive to lipid peroxidation (Bindoli, 1988). Mitochondrial dysfunction resulting from lipid peroxidation may lead to compromise in a cells capability to maintain energy levels, energy failure, and the triggering of events leading to neuronal injury and death.

Marked alterations in membrane phospholipid metabolism result in the liberation of free fatty acids such as arachidonic acid, diacylglycerols, eicosanoids, lipid peroxides and free radicals (Costa, 1994). $\mathrm{Ca}^{2+}$-dependent activation of phospholipase $\mathrm{A}_{2}$ releases arachidonic acid (Erakovic et al., 1997; Mrsic et al., 1997) yielding $\mathrm{O}_{2} \cdot{ }^{-}$through metabolism by lipoxygeneses (Coyle and Puttfarcken, 1993). These lipid metabolites in conjunction with abnormal ion homeostasis and decreased energy generation may contribute to cell injury and death (Pellegrini-Giampietro et al., 1988; Shimizu and Wolfe, 1990; Simmet and Peskar, 1990). $\mathrm{F}(2)$-isoprostanes ( $\mathrm{F}_{2}$-IsoPs) are a novel class of prostaglandin $\mathrm{F}_{2}\left(\mathrm{PGF}_{2}\right)$-like compound produced by a non-cyclooxygenase and free radical catalyzed mechanism involving the peroxidation of arachidonic acid. $F_{2}$-IsoPs are often utilized as an index of lipid peroxidation in vivo because they are specific products of lipid peroxidation, detectable 
in normal biological fluids, increase dramatically in models of oxidant injury, modulated by antioxidant status, and are unaffected by dietary lipids (Roberts and Morrow, 2000). $\mathrm{F}_{2^{-}}$ IsoPs are a validated, sensitive, stable and reliable marker of free radical-induced lipid peroxidation. A large increase in prostaglandin derivatives, including prostaglandin- $\mathrm{F}_{2} \alpha$ a precursor of $\mathrm{F}_{2}$-IsoP, is increased after prolonged seizures. $\mathrm{F}_{2}$-IsoPs have been measured in microdissected dentate gyrus, CA1, and CA3 regions following KA treatment and shown to be elevated in CA3 at $16 \mathrm{~h}$ and correlated with neuronal loss and mitochondrial aconitase inactivation (Patel et al., 2001). Interestingly, the dentate gyrus showed a 2.5-5 fold increase between $8-24 \mathrm{~h}$ post-KA, even though the dentate gyrus is normally resistant to KA-induced neuronal death.

Isofurans (IsoF), a novel product of lipid peroxidation, have also shown to be elevated following KA-induced seizures with an overlapping but distinct time course as that of $\mathrm{F}_{2}$ IsoPs in hippocampal subregions (Patel et al., 2008). The expression of IsoF's, but not $F_{2^{-}}$ IsoPs, coincided with timepoints of mitochondrial oxidative stress. Seizure-induced $\mathrm{F}_{2}$-IsoP formation coincided with the peak hypoxia phase in affected tissues whereas IsoF formation coincide with the reoxygenation phase in this study, suggesting seizure-induced changes in tissue oxygen levels and mitochondrial dysfunction may differentially influence the formation of $\mathrm{F}_{2}$-IsoPs and IsoFs. The combined measurement of both IsoFs and $\mathrm{F}_{2}$-IsoPs provides a more reliable assessment of seizure-induced oxidative stress and changes in tissue oxygenation. These results suggest that oxidative damage to lipids results from seizure activity and may play an important role in seizure-induced death of vulnerable neurons.

Malondialdehyde (MDA) and 4-hydroxy-2-(E)-nonenal (4-HNE) have been used to identify oxidative damage to lipids and its association with ageing and disease (Dexter et al., 1989; Cini and Moretti, 1995). MDA levels have been reported to be increased at 8 and $16 \mathrm{~h}$ following KA treatment, and decreased at $48 \mathrm{~h}$ and $5 \mathrm{~d}$ in the CA3 and dentate gyrus of adult rats (Bruce and Baudry, 1995). MDA has also been reported to increase $2 \mathrm{~h}$ postpilocarpine-induced SE in the cortex (Tejada et al., 2007). In an amygdala kindling model of epilepsy, MDA and 4-HNE have been reported to increase in both hemispheres $24 \mathrm{~h}$ following the last seizure (Frantseva et al., 2000b). Vit E and GSH prevented the rise in lipid peroxides and hippocampal neuronal death during kindling, but did not arrest the development of seizures. The thiobarbituric acid reactive substances (TBARS) assay revealed increased lipid oxidation following KA-induced seizures as early as $4 \mathrm{~h}$ in the cortex, hippocampus, basal ganglia, and cerebellum, which remained elevated at $24 \mathrm{~h}$ in the hippocampus and cerebellum (Gluck et al., 2000). In both the KA and pilocarpine models, TBARS were reportedly increased $12-14 \mathrm{~h}$ post-treatment, which decreased or reached basal levels at chronic time points suggesting hypometabolism, neuronal loss, and compensatory mechanisms may be actively modulating enzymes related to ROS catabolism (Dal-Pizzol et al., 2000). In the lithium-pilocarpine model, increased whole brain free fatty acids (FFA), a marker of membrane phospholipid metabolism, have been reported 1 and $2.5 \mathrm{~h}$ posttreatment (Erakovic et al., 2000). Hydroperoxide, another marker of lipid peroxidation, has been reported to be increased at $1 \mathrm{~h}$ post-pilocarpine treatment (Bellissimo et al., 2001). Lipid radicals have been detected in the extracellular space during KA-induced seizure activity using in vivo electron spin resonance microdialysis in freely moving rats (Ueda et al., 1997), suggesting a progression of lipid peroxidation during seizure activity which may lead to neuronal damage in the hippocampus following acute seizure activity.

A variety of lipid peroxidation assays have been used as evidence of free radical damage in neuropathological processes. However, the in vivo use of these assays is associated with problems such as end product instability, lack of sensitivity, and inadequate specificity for free radical mediated processes. For example, the TBARS assay is not specific for lipid peroxidation and the use of MDA as an indicator of lipid peroxidation may be problematic 
due to tissue homogenization and organic solvent extraction steps (Cohen et al., 1987). Nonetheless, there is sufficient evidence to support the presence of lipid peroxidation products and mitochondrial dysfunction associated with seizure activity.

\subsection{Seizure-induced oxidative damage to mtDNA}

Oxidative damage to mtDNA and its consequences such as gene mutation and deletions have long been implicated in the pathogenesis of a variety of human disorders associated with mitochondrial dysfunction and ageing (Tritschler and Medori, 1993) and have recently begun to be investigated as a potential contributor to epileptogenesis. Oxidative damage to DNA can be variable, producing structural damage such a strand breaks, protein/DNA cross links, and/or modification of base pairs. mtDNA lack protective histones, is located in close proximity to the inner mitochondrial membrane where ROS are generated, lacks introns leading to genomic injury adversely affecting a coding region for the ETC or mitochondrial translational machinery, has a high transcription rate leading to an increased probability of mutations and/or deletions, and possess less efficient repair mechanisms then nDNA under certain circumstances (Yakes and Van Houten, 1997; Jarrett et al., 2008a). These characteristics result in the mitochondrial genome being particularly vulnerable to ROSinduced damage (Bohr et al., 2002). As such, levels of oxidized bases in mtDNA are 2-3 times higher than nDNA (Richter et al., 1988; Hudson et al., 1998). Increased production of ROS may cause mtDNA damage leading to decreased activities of mitochondrial ETC complexes containing mtDNA-encoded subunits and selectively diminishing the activities of complexes I, III, IV, and V (Fig. 1). A decrease in mtDNA quantity in CA1 and CA3 $30 \mathrm{~d}$ post-pilocarpine treatment in rats has been reported (Kudin et al., 2002). However, an alternative study reported no mtDNA abnormalities $120 \mathrm{~d}$ post-pilocarpine-induced SE, suggesting that free radicals produced during SE do not adversely effect nuclear integrity during chronic epilepsy (Nasseh et al., 2006). Differences in the results from these studies may be based on the use of different nuclear probes during mtDNA quantification by Southern blotting.

Two commonly used markers of oxidative DNA damage are thymine glycol (TG) and 8OHdG. TG is an adduct which can lead to cell death by blocking polymerase action (Ames, 1989; Dizdaroglu, 1993). 8-OHdG, an oxidatively modified guanine adduct, is one of the most common adducts formed from oxidation of DNA (Dizdaroglu, 1991) and has been used as an index of oxidative DNA damage with the ratio of steady state levels of 8-OHdG to 2-deoxyguanine (2-dG) (Shigenaga et al., 1990; Mecocci et al., 1993; Giulivi et al., 1995; Jarrett et al., 2008a). 8-OHdG lesions are highly mutagenic because they can mispair with adenine leading to a transversion mutation (Grollman and Moriya, 1993) and DNA polymerase will insert a wrong base opposite $8-\mathrm{OHdG}$ about $27 \%$ of the time (Pinz et al., 1995). However, the accurate measurement of $8-\mathrm{OHdG}$ is challenging due to the possibility of introduction of artificial oxidation during sample isolation and preparation. A timedependent increase in mitochondrial, but not nuclear, $8-\mathrm{OHdG} / 2 \mathrm{dG} 16-48 \mathrm{~h}$ following KA treatment has been reported with a corresponding increase in mtDNA lesion frequency (Jarrett et al., 2008a). These changes were correlated with increased mitochondrial $\mathrm{H}_{2} \mathrm{O}_{2}$ production and decreased aconitase activity accompanied by a transient decrease in mtDNA repair.

8-OHdG can activate DNA repair systems that involve enzymatic processes including base recognition and excision to ligation of DNA strands. Short and long patch DNA base excision repair (BER) appears to be the predominant mechanism for the repair of oxidative DNA lesions in the mitochondria (Croteau and Bohr, 1997; LeDoux et al., 2007; Akbari et al., 2008; Liu et al., 2008; Szczesny et al., 2008) and its impairment and/or imbalance has been implicated in neuronal dysfunction (Audebert et al., 2002; Fishel et al., 2003; Beal, 
2005; Harrison et al., 2005; Neema et al., 2005; Quach et al., 2005; Fishel et al., 2007). The mitochondrial base excision repair pathway (mtBER) involves a highly coordinated process catalyzed by the sequential actions of the DNA repair enzymes 8-oxoguanine glycosylase (Ogg1) and DNA polymerase gamma (Pol $\gamma$ ). Ogg1 and Pol $\gamma$ mRNA and protein levels are elevated between $24 \mathrm{~h}$ and $3 \mathrm{wk}$ following KA-induced SE, followed by improvement in mtDNA repair (Jarrett et al., 2008a). Spontaneous seizures coincided with accumulation of mtDNA damage, increased mitochondrial $\mathrm{H}_{2} \mathrm{O}_{2}$, decreased $\mathrm{Ogg} 1$ and $\mathrm{Pol} \gamma$, and impaired mtDNA repair in this study, suggesting a role for the contribution of mitochondrial injury to epileptogenesis. Although various reports have demonstrated changes in BER during several neuronal disorders such as stroke, Alzheimer's disease, and amyotrophic lateral sclerosis (Kisby et al., 1997; Copani et al., 2006; Li et al., 2006; Coppede et al., 2007), its role in epilepsy requires further exploration. The isolation of pure mitochondria is often necessary for assays aimed at determining mtDNA damage and repair, which can lead to artifactual DNA damage. To circumvent this problem, a gene- and genomic-specific quantitative extended-length polymerase chain reaction (PCR) assay has been developed that can detect oxidative mtDNA damage and repair based on relative magnitudes of gene fragment amplification (Yakes and Van Houten, 1997; Ayala-Torres et al., 2000; Santos et al., 2006).

\subsection{Seizure-induced alterations in antioxidant defenses and redox status}

\subsubsection{Seizure-induced alterations in antioxidant defenses}

Endogenous antioxidant defenses are a complex and integrated system that functions to protect cells against the deleterious effects of ROS. When antioxidants cannot breakdown ROS efficiently, oxidative damage occurs and accumulates, particularly in the mitochondria (Sies, 1993; James and Murphy, 2002). Superoxide dismutase (SOD) is an endogenous enzymatic antioxidant that has been shown to protect against programmed cell death (Rothstein et al., 1994b; Greenlund et al., 1995) and exists in three forms; CuZnSOD (SOD1) localized in the cytoplasm, MnSOD (SOD2) localized in the mitochondrial matrix, and ECSOD (SOD3), localized in the extracellular space. The dismutation of $\mathrm{O}_{2} \cdot{ }^{-}$occurs via $\mathrm{SOD}$, which produces $\mathrm{H}_{2} \mathrm{O}_{2}$ that is further broken down to $\mathrm{O}_{2}$ and $\mathrm{H}_{2} \mathrm{O}$ during normal conditions by catalase (CAT) and glutathione peroxidase (GPx) in a reaction that uses GSH as a co-substrate. If not adequately controlled, $\mathrm{O}_{2}{ }^{-}$production can lead to the formation of more potent oxidants, such $\mathrm{OH}^{-}{ }^{-}$, which can produce further oxidative damage and contribute to cell death (Fig. 1). Genetic inactivation of SOD1 or SOD3 results in mild phenotypes (Carlsson et al., 1995; Reaume et al., 1996) while mice completely lacking SOD2 are lethally affected by three weeks (Li et al., 1995; Huang et al., 2001), have spontaneous seizures (Lynn et al., 2005), and show no signs of compensation by increased expression of either SOD1 or SOD3 (Van Remmen et al., 1999). Hence, SOD2 is critically important as an antioxidant defense due to its proximity to the mitochondria and the primary source of $\mathrm{O}_{2} \cdot{ }^{-}$generation.

Seizure-associated alterations to antioxidant defenses are a common finding, but whether antioxidant levels are increased or decreased remains controversial. Following KA-induced SE, increases in SOD and CAT have been measured as early at $48 \mathrm{~h}$ and $5 \mathrm{~d}$ in both piriform cortex and hippocampus (Bruce and Baudry, 1995). These changes correspond to a period of glial activation, proliferation, and degeneration of susceptible neuronal cells suggesting immediate compensation of these scavenging enzymes are not necessarily neuroprotective (Altar and Baudry, 1990). CAT activity has been reported to increase in the hippocampus, striatum, and frontal cortex but not in the cerebellum $1 \mathrm{hr}$ post-pilocarpine treatment (Freitas et al., 2004), suggesting alterations in antioxidant defenses as a result of SE. Also in the pilocarpine model, CAT, GPx, and SOD were reportedly increased in the cortex $2 \mathrm{~h}$ post-SE (Tejada et al., 2007). SOD increased in a whole brain preparation $30 \mathrm{~d}$ post-amygdaloid kindling, and direct amagdalyoid injection of SOD1 suppressed the production of seizures 
(Mori et al., 1991). In the lithium-pilocarpine model, a decrease in GPx and no change in SOD has been reported, suggesting impaired and not increased antioxidant defense in the brain, particularly in the cortex (Erakovic et al., 2000). Using spectrophotometric methods in the pilocarpine model, hippocampal SOD has been reported to decrease at $24 \mathrm{~h}$ and during the chronic phase of epilepsy, while GPx increased only at $1 \mathrm{~h}$ post-treatment (Bellissimo et al., 2001). Twenty four hours post-pilocarpine treatment, hippocampal CAT, but not SOD, was reportedly decreased suggesting the hippocampus does not use SOD as the major free radical scavenging system, but perhaps uses CAT and/or GSH (Freitas et al., 2005). A decrease in regional brain antioxidant levels have also been reported using the electroconvulsive shock treatment in rats (Erakovic et al., 2000) lasting up to $48 \mathrm{~h}$ after a single seizure episode. (See Devi et al., 2008 for a list of the effects of antioxidants on experimental seizures). Considering the disparity in the evidence from a variety of animal models of epilepsy, the issue of endogenous antioxidant compensation in response to seizure activity remains unresolved.

\subsubsection{Seizure-induced alterations in redox status}

An alternative to the measurement of oxidized cellular targets as markers of oxidative stress has been to directly measure a subcellular redox couple as an indication of redox status. GSH is the most abundant intracellular non-enzymatic oxidant defense in the body (Meister and Anderson, 1983). The oxidation of GSH is coupled to the reduction of GPx to catalyze the removal of $\mathrm{H}_{2} \mathrm{O}_{2}$ in cells. GSH is recycled from GSSG, its disulfide redox partner, by glutathione reductase (GR) and NADPH oxidation (Fig. 1). GSH/GSSG is a commonly used biomarker of oxidative stress in biological systems (Reed and Savage, 1995). A decrease in GSH and GSSG levels suggest an alteration in GSH synthesis and/or transport. Decreased ratios of GSH/GSSG could induce structural damage to mitochondrial membranes, changes in mitochondrial enzyme activities and membrane potential, and subsequent mitochondrial dysfunction potentially affecting neuronal excitability.

A decrease in both GSH levels and GR activity has been reported in brain regions and plasma of epileptic patients (Mueller et al., 2001; Sudha et al., 2001). Animal models of epilepsy have provided inconsistent results concerning alterations in redox status. Certain studies provide evidence of a decrease in hippocampal redox status following SE (Skaper et al., 1999; Gilberti and Trombetta, 2000; Ong et al., 2000), while others report no change (Gluck et al., 2000; Gupta et al., 2002). In a study reporting no changes in GSH levels, GSSH was found to increase at $4 \mathrm{~h}$ post-SE in the cortex, suggesting that GSH may play a disproportionate role in the cortex but not in the hippocampus during epileptogenesis (Gluck et al., 2000). A time-dependent decrease in the GSH/GSSG ratio following KA-induced SE as measured by HPLC has been reported in mitochondrial fractions as compared to whole hippocampal homogenates (Liang and Patel, 2006). This altered redox status was accompanied by a moderate increase in GPx activity and a decrease in GR activity in hippocampal homogenates and mitochondria, respectively. Interestingly, the time course of redox changes preceded aconitase inactivation suggesting that the latter may further deplete GSH because reducing equivalents are used to reactivate aconitase. Alternately, the increased free radical load due to aconitase inactivation (i.e. $\mathrm{H}_{2} \mathrm{O}_{2}$ and iron) may further deplete GSH. This study demonstrated that mitochondrial GSH depletion occurs early after SE and is persistent even during the "latent period". Pilocarpine-induced SE has been reported to decrease GSH in the hippocampus 24 h post-treatment (Freitas et al., 2005). In the kindling model, a persistent decrease in GSH was observed at $4 \mathrm{~h}$ post stimulation in CA3 which preceded a transient decrease in mitochondrial ETC complex I activity and aconitase levels, suggesting GSH as an early and critical determinant of later neuronal death and dysfunction (Sleven et al., 2006a). These observations are consistent with the notion that mitochondria contribute disproportionately to SE-induced oxidative stress. 
Although GSH/GSSG measurements are an important tool in the measurement of redox status and oxidative stress, their levels may be augmented during subcelllar fractionation. Alternatively, coenzyme A (CoASH) and its disulfide with GSH (CoAssG), which are primarily compartmentalized within mitochondria (Fig. 1), can be measured in whole tissue homogenates. It has been reported that CoASH/CoASSG ratios decreased in hippocampal tissue following KA-induced SE at a time course paralleling mitochondrial GSH/GSSG levels (Liang and Patel, 2006). Increases in mitochondrial $\mathrm{O}_{2} \cdot{ }^{-}$and $\mathrm{H}_{2} \mathrm{O}_{2}$ and aconitase inactivation are likely mechanisms that may contribute to the decreased mitochondrial GSH/ GSSG and CoASH/CoASSG ratios measured following seizures. Cysteine, a rate limiting precursor of GSH, was also decreased following SE in both hippocampal tissue homogenates and mitochondrial fractions (Liang and Patel, 2006). Extensive neuronal death in the CA3 subfield occurs from 2-7 days following KA treatment (Liang et al., 2000; Patel et al., 2001) after the early onset of reported redox changes, suggesting altered redox status may contribute to seizure-induced neuronal death. The decrease in mitochondrial GSH/ GSSG and tissue CoASH/CoASSG as early as $8 \mathrm{~h}$ after KA treatment precedes the earliest inactivation of aconitase as well as increases in IsoF and 8OHdG/2DG, suggesting that mitochondrial thiol status may play a key role in mediating SE-induced oxidative damage.

\subsection{Targeting mitochondrial oxidative stress in epilepsy therapy}

Although significant progress has been made in the development of new antiepileptic drugs, approximately one-third of patients are refractory to currently available treatments. Epilepsy therapies are largely aimed at decreasing neuronal excitability and thereby controlling the occurrence of epileptic seizures. An alternative approach is the targeting of epileptogenesis with drugs designed towards the underlying processes that lead to the development of epilepsy. The targeting of excitotoxicity resulting from a disruption of $\mathrm{Ca}^{2+}$ homeostasis leading to neuronal damage and death with antiepileptic drugs has recently begun to be explored (Rho and Sankar, 1999; Trojnar et al., 2002; Sankar and Holmes, 2004). Excessive $\mathrm{Ca}^{2+}$ uptake during excitotoxic insults has been shown to increase mitochondrial ROS, inhibit ATP synthesis, promote cytochrome $\mathrm{c}$ release, and activate the MPT leading to cell death (Sullivan et al., 2005). Although it is clear that mitochondrial ROS and free radicals leading to mitochondrial oxidative stress and dysfunction are active during epileptogenesis (Fig. 2), the specificity of radicals and their origins are unclear. These findings raise the possibility that inhibition of mitochondrial dysfunction may in part underlie the successful treatment of epilepsy.

\subsubsection{Antioxidant therapies}

Testing antiepileptogenic therapies aimed at mitochondrial bioenergetics and oxidative stress pathways has largely been limited to animal studies. Recent studies suggest the association of seizures and SE with oxidative stress (Liang and Patel, 2006; Barros et al., 2007; Jarrett et al., 2008a). Levetiracetam, a novel antiepileptic drug, given during selfsustained SE and up to $44 \mathrm{~h}$ following seizure onset rescued changes to GSH, aconitase, citrate synthase, complex I, and alpha-ketoglutarate dehydrogenase (Gibbs et al., 2006). Also, it improved behavioral seizures but did not affect EEG parameters suggesting neuroprotection rather than a direct effect on seizures themselves (Gibbs et al., 2006). A current antiepileptic drug, zonisamide, which mainly acts through the inhibition of $\mathrm{Na}^{+}$ channels, also has antioxidant properties enhancing its neuroprotective characteristics (Mori et al., 1998; Tokumaru et al., 2000). Antioxidants such as the spin trapping agent N-tertbutyl- $\alpha$-phenylnitrone $(\mathrm{PBN})$ and vitamin $\mathrm{E}$ are known to accumulate in the mitochondria (Bjorneboe et al., 1991; Folbergrova et al., 1995). PBN has been shown to prevent ROSinduced damage to the ETC, maintain levels of high energy phosphates (Gupta et al., 2001), and inhibit KA-induced NO generation (Milatovic et al., 2001). Rats delivered acetylcholinesterase inhibitor-induced SE and pre-treated with PBN showed prevention of 
both seizures and loss of high energy phosphates, while animals pre-treated with vitamin $\mathrm{E}$ showed a prevention of high energy phosphates without affecting seizures (Gupta et al., 2001). Vitamin E has been shown to have antioxidant and neuroprotective effects in pilocarpine-induced seizures and to prevent increased brain free fatty acid levels and increased CAT levels in rats (Barros et al., 2007), suggesting its protection may be mediated by antioxidant enzymatic activity. Vitamin E and GSH have been demonstrated to attenuate the rise in lipid peroxides and hippocampal cell death during kindling but not arrest the development of seizures (Frantseva et al., 2000b). However, intra-peritoneal injection of Nacetyl-L-cysteine (NAC), a GSH precursor, did not protect against diminished GSH following perforant path stimulation-induced SE and did not protect against mitochondrial dysfunction (Sleven et al., 2006b). Vitamin E has been shown to slow the onset of seizures in the ferrous chloride model but have little to no effect using the PTZ-threshold, electroshock, kindling, and KA models (Levy et al., 1990; Levy et al., 1992; Xu and Stringer, 2008). A study of vitamin $\mathrm{E}$ in children with epilepsy demonstrated a significant decrease in seizure frequency over 3 months using a randomized double-blind experimental design (Ogunmekan and Hwang, 1989). However, clinical trials of vitamin E as on add-on therapy for refractory epilepsy have been controversial, with largely failed attempts to influence the occurrence of epileptic seizures in pediatric patients.

Vitamin $\mathrm{C}$ has been suggested to exert potent anticonvulsant and neuroprotective effects (Xavier et al., 2007). The neuroprotective effects of vitamin C pre-treatment in pilocarpinetreated rats have been attributed to reduced lipid peroxidation and increased CAT activity following SE (Santos et al., 2008). Vitamin C has been demonstrated to increase the latency to first seizure and decrease the mean seizure score in the pilocarpine model, reduce mortality in the PTZ model, be effective against penicillin-induced seizures (Ayyildiz et al., 2007), but be ineffective in the KA model (Xu and Stringer, 2008). D,L- $\alpha$-lipoic acid is a naturally occurring cellular component which has been reported as a scavenger of ROS (Packer et al., 1995; Packer et al., 1997; Bast and Haenen, 2003). $\alpha$-lipoic acid pre-treatment has been demonstrated to decrease seizure activity using ferric chloride-induced seizures (Meyerhoff et al., 2004) and increase the latency to first seizure using the pilocarpine model, but have no significant effects in the PTZ and KA models (Xu and Stringer, 2008).

Melatonin is a natural occurring compound produced by the pineal gland that has antioxidant properties and effects on mitochondrial oxidative stress implicated in neuronal diseases (Reiter et al., 1994; Reiter, 1998; Leon et al., 2004). The protective effects of melatonin have been reported in human epilepsy (Molina-Carballo et al., 1997) and in the PTZ model of epilepsy (Bikjdaouene et al., 2003) where its antiepileptic effects have been attributed to the regulation of GABA receptors and inhibition of glutamate mediated responses through nNOS activity and NO production (Acuna-Castroviejo et al., 1995; Leon et al., 2000; Bikjdaouene et al., 2003). However, an alternative study reported no significant effects of melatonin using the PTZ and KA models (Xu and Stringer, 2008). Melatonin has been shown to decrease iron-induced seizures (Kabuto et al., 1998), increase the latency to epileptiform activity using penicillin-induced seizures (Yildirim and Marangoz, 2006), and increase the latency to first seizure in the pilocarpine model (Xu and Stringer, 2008).

Melatonin has been reported to reduce the deleterious effects of KA-induced SE on nuclear and mtDNA, lipid peroxidation, hippocampal cell loss, and seizures in rats and mice (Tan et al., 1998; Tang et al., 1998; Mohanan and Yamamoto, 2002; Yamamoto and Mohanan, 2003) as well as ROS production, decreased GSH, and complex II activity (Dabbeni-Sala et al., 2001). The ability of melatonin to act as a potent antioxidant, protect mitochondrial ROS homeostasis, and interact with mtDNA makes it a novel target therapy for use in controlling mitochondrial bioenergetics and disease. However, different mechanisms of action may occur in different models and/or epileptic syndromes complicating treatments. Additionally, activated pathways may be producing deleterious results alone, or in conjunction with other pathways. While particular antioxidants have been shown to be effective in specific 
chemoconvulsant models, the same antioxidants may not be effective in alternative models, suggesting that their effects may be model specific (Xu and Stringer, 2008). Therapies aimed at mitochondrial bioenergetics and oxidative stress pathways, however, may provide a novel avenue for therapeutic intervention for the treatment of epilepsies.

\subsubsection{Synthetic antioxidant therapies}

The use of SOD and CAT as therapeutic agents to attenuate ROS-induced injury responses has had mixed success (Shaffer et al., 1987; Thibeault et al., 1991; Wispe et al., 1992; Lardot et al., 1996; Simonson et al., 1997) based primarily on their large size which limits cell permeability, short circulating half-life, antigenicity, and expense. An increasing number of SOD mimetics have been developed to overcome some of inherent limitations of these natural antioxidants. Oxidative stress and neuronal damage induced by SE or a deficiency in SOD2 have been demonstrated to be ameliorated by the SOD mimetics, MnTBAP, and the salen EUK compounds (Liang et al., 2000; Melov et al., 2001; Hinerfeld et al., 2004). However, acute administration of these catalytic antioxidants did not alter chemoconvulsant-induced behavioral seizure severity. MnTBAP has been shown to protect mitochondrial aconitase, $8-\mathrm{OHdG}$ formation, and hippocampal neuronal loss in rats treated with KA (Liang et al., 2000) and to inhibit both necrotic and apoptotic cell death (Patel, 1996; Patel, 1998), strengthening the role of oxidative mechanisms in KA neurotoxicity. MnTBAP has also been shown to rescue the lethal phenotype and extend the lifespan of Sod2 $2^{-/-}$mice (Melov et al., 1998), prevent aconitase inactivation and cell death following NMDA application in cortical cultures (Patel, 1996), and protect mtDNA from oxidative damage in cultured fibroblasts (Milano and Day, 2000). Although the exact cellular site where MnTBAP performs its antioxidant abilities is currently unknown, a likely mechanism of action is the protection of cellular targets by scavenging intracellular reactive species such as $\mathrm{O}_{2} \cdot{ }^{-}, \mathrm{H}_{2} \mathrm{O}_{2}, \mathrm{ONOO}^{-}$and lipid peroxides (Patel and Day, 1999).

Synthetic antioxidants that protect mitochondrial targets and decrease neuronal death may be useful supplements for the clinical management of patients with SE or intractable epilepsy. The AEOL class of metalloporphyrin compounds contain a manganese center that are capable of detoxifying a wide range of ROS such as $\mathrm{O}_{2} \cdot{ }^{-}, \mathrm{H}_{2} \mathrm{O}_{2}, \mathrm{ONOO}^{-}$, and lipid peroxide radicals (Patel and Day, 1999). Several water-soluble metalloporphyrin compounds have been shown to be effective in animal models of epilepsy (Liang et al., 2000), stroke (Mackensen et al., 2001) and amyotrophic lateral sclerosis (Crow et al., 2005) and may provide important tools in targeting neuroprotection and the pathogenesis of neurological disorders. Chelatable iron is an important catalyst for the initiation and propagation of free radical reactions implicated in the pathogenesis of neuronal disorders such as epilepsy. KAinduced SE has been shown to result in a time-dependent increase in chelatable iron in mitochondrial fractions of the rat hippocampus (Liang et al., 2008). N,N'-bis (2hydroxybenzyl) ethylenediamine- $N, N^{\prime}$-diacetic acid (HBED), a synthetic iron chelator, administered systemically ameliorated SE-induced changes in chelatable iron, mtDNA damage assessed by 8-OHdG, GSH depletion, and hippocampal cell loss, suggesting a role for mitochondrial iron in the pathogenesis of SE-induced brain damage and subcellular iron chelation as a novel therapeutic approach for its management (Liang et al., 2008). However, in studies investigating oxidative stress as a potential therapeutic target it should be noted that ROS play an important physiological role in cell signaling and their removal with antioxidants may have deleterious consequences on cellular functions during chronic administration that remain to be elucidated. Novel therapies targeting mitochondrial bioenergetics and oxidative stress that are neuroprotective and ameliorate consequences of SE may be useful in the management of epilepsy and attenuation of its development. 


\subsubsection{Non-pharmacological therapy}

Non-pharmacological therapies such as the ketogenic diet (KD) have been explored as a means of attenuating seizures by targeting mitochondrial bioenergetics and metabolism. The $\mathrm{KD}$ is often a successful treatment for children with epilepsy when pharmacological treatment is unreliable suggesting that the diet works by unique mechanisms. The KD was developed as a therapy for intractable seizures in children in the 1920's (Schwartzkroin, 1999) and is based on the intake of high-fat/low-carbohydrate/low-protein leading to a switch from glucose metabolism to the generation and metabolism of ketones. Rats fed this diet have been shown to undergo ketosis, which is necessary for the diet's anticonvulsant effect and positively correlated with seizure protection (Bough et al., 1999; Stafstrom, 1999).

Currently, there is a lack of understanding regarding the precise mechanisms underlying the KD. Two theories proposed to account for the effects of the diet include the neuroprotection of ketone bodies ( $\beta$-hydroxybutyrate, acetoacetate, and acetone) (Massieu et al., 2003; Mejia-Toiber et al., 2006; Noh et al., 2006; Kim do et al., 2007), and the anticonvulsant effects of glycolysis inhibition (Schwechter et al., 2002; Garriga-Canut et al., 2006). The application of ketone bodies to a midbrain slice preparation has been demonstrated to slow spontaneous firing of GABAergic neurons in the substantia nigra (Ma et al., 2007). However, in a hippocampal slice preparation, neither $\beta$-hydroxybutyrate or acetoacetate affected the frequency or duration of epileptiform discharges (Thio et al., 2000). A role for mitochondrial bioenergetics has also been suggested to underlie the protective effects of the KD. For example, the KD has been shown to produce mitochondrial biogenesis (Bough et al., 2006), a decrease in mitochondrial ROS (Maalouf et al., 2007) due to upregulation of the uncoupling protein UCP2 (Sullivan et al., 2004), increase the cellular antioxidant capacity (Ziegler et al., 2003; Costello and Delanty, 2004; Nazarewicz et al., 2007), and in vitro studies have demonstrated that ketosis byproducts have the ability to prevent mtDNA deletions and cell death (Yamamoto and Mohanan, 2003; Santra et al., 2004). The KD has recently been demonstrated to improve the mitochondrial redox status in rats fed the diet for 3 weeks, which may improve the ability of the brain to resist metabolic changes and oxidative stress which partly underlies the occurrence of seizures (Jarrett et al., 2008b). This study also demonstrated an increase in mitochondrial GSH levels and stimulation of its de novo biosynthesis, and an improvement in mitochondrial redox status in the hippocampus resulting in decreased mitochondrial ROS production and protection of mtDNA. These results suggest increased GSH as a possible candidate mechanism underlying the protection observed by the KD. Currently, all of the contributing mechanisms to the anticonvulsant effects of the KD remain unknown and warrant a greater understanding.

\subsection{Conclusions}

This review provides an overview of the role of mitochondrial oxidative stress and dysfunction in seizure-induced neuronal damage and a potential contributing factor in epileptogenesis. Mitochondria dysfunction can affect ROS production, macromolecule function, bioenergetics, glutamate excitotoxicity, neuronal death, and neuronal excitability. Each of these targets is crucial for normal brain function, and dysfunction in one or more of them may decrease seizure threshold causing the brain to be more susceptible to becoming epileptic. Targeting mitochondrial bioenergetics and oxidative stress with antioxidant and non-pharmacological treatments may prove to be useful in the management of epilepsy and attenuation of its development. Continued research in this area will provide a greater understanding of how mitochondrial oxidative stress and dysfunction contributes to the pathogenesis of TLE and how therapeutic strategies targeting mitochondrial bioenergetics can be used for patients refractory to current antiepileptic treatments. 


\section{Acknowledgments}

The authors wish to thank David Cantu for contributions to Figure 1.

\section{Index of Abbreviations}

TLE

SE

KA

Li

SOD

GSH

ROS

mtDNA

ETC

ATP

TCA

MPT

$\mathrm{OH}^{-}$

$\mathrm{H}_{2} \mathrm{O}_{2}$

$\mathrm{O}_{2}$ - $^{-}$

NO

$\mathrm{ONOO}^{-}$

8-OHdG

MnSOD (SOD2)

GS

PTZ

NMDA

$\mathrm{F}_{2}$-IsoP

IsoF

MDA

4-HNE

TBARS

Ogg1

Pol $\gamma$

BER

CAT

GPx

GR temporal lobe epilepsy

status epilepticus

kainic acid

Pilo-lithium-pilocarpine

superoxide dismutase

glutathione

reactive oxygen species

mitochondrial deoxyribonucleic acid

electron transport chain

adenosine triphosphate

tricarboxylic acid cycle

mitochondrial permeability transition pore

hydroxyl radical

hydrogen peroxide

superoxide radical

nitric oxide

peroxynitrite

8-hydroxy-2-deoxyguanosine

manganese superoxide dismutase

glutamine synthetase

pentylenetetrazole

$\mathrm{N}$-methyl-D-aspartic acid

$\mathrm{F}(2)$-isoprostanes

isofurans

malondialdehyde

4-hydroxy-2-(E)-nonenal

thiobarbituric acid reactive substances

8-oxoguanine glycosylase

DNA polymerase gamma

base excision repair

catalase

glutathione peroxidase

glutathione reductase 


$\begin{array}{ll}\text { CoASH } & \text { coenzyme A } \\ \text { MnTBAP } & \text { manganese 5,10,15,20-tetrakis (4-benzoic acid) porphyrin } \\ \text { KD } & \text { ketogenic diet } \\ \text { BK }_{\text {Ca }} & \text { large conductance } \mathrm{Ca}^{2+} \text {-activated } \mathrm{K}^{+} \text {channels } \\ \text { DNTB } & 5,5^{\prime} \text {-dithio-bis(2-nitrobenzoic acid) } \\ \text { DTT } & \text { dithiothreitol } \\ \text { mitoK }_{\text {ATP }} & \text { mitochondrial ATP-sensitive } \mathrm{K}^{+} \text {channel } \\ \mathbf{I}_{\mathbf{N a}, \mathbf{p}} & \text { inactivation-resistant TTX-sensitive } \mathrm{Na}^{+} \text {current }\end{array}$

\section{References}

Acuna-Castroviejo D, Escames G, Macias M, Hoyos A. Munoz, Carballo A. Molina, Arauzo M, Montes R. Cell protective role of melatonin in the brain. J Pineal Res. 1995; 19(2):57-63. [PubMed: 8609597]

Aizenman E, Hartnett KA. The action of CGS-19755 on the redox enhancement of NMDA toxicity in rat cortical neurons in vitro. Brain Res. 1992; 585(1-2):28-34. [PubMed: 1511311]

Akbar MT, Rattray M, Williams RJ, Chong NW, Meldrum BS. Reduction of GABA and glutamate transporter messenger RNAs in the severe-seizure genetically epilepsy-prone rat. Neuroscience. 1998; 85(4):1235-51. [PubMed: 9681960]

Akbari M, Visnes T, Krokan HE, Otterlei M. Mitochondrial base excision repair of uracil and AP sites takes place by single-nucleotide insertion and long-patch DNA synthesis. DNA Repair (Amst). 2008; 7(4):605-16. [PubMed: 18295553]

Alonso A, Llinas RR. Subthreshold Na+-dependent theta-like rhythmicity in stellate cells of entorhinal cortex layer II. Nature. 1989; 342(6246):175-7. [PubMed: 2812013]

Altar CA, Baudry M. Systemic injection of kainic acid: gliosis in olfactory and limbic brain regions quantified with [3H]PK 11195 binding autoradiography. Exp Neurol. 1990; 109(3):333-41. [PubMed: 2209775]

Amato A, Connolly CN, Moss SJ, Smart TG. Modulation of neuronal and recombinant GABAA receptors by redox reagents. J Physiol. 1999; 517(Pt 1):35-50. [PubMed: 10226147]

Ames BN. Endogenous oxidative DNA damage, aging, and cancer. Free Radic Res Commun. 1989; 7(3-6):121-8. [PubMed: 2684796]

Amitai Y. Membrane potential oscillations underlying firing patterns in neocortical neurons. Neuroscience. 1994; 63(1):151-61. [PubMed: 7898645]

Angelova P, Muller W. Oxidative modulation of the transient potassium current IA by intracellular arachidonic acid in rat CA1 pyramidal neurons. Eur J Neurosci. 2006; 23(9):2375-84. [PubMed: 16706845]

Angelova PR, Muller WS. Arachidonic acid potently inhibits both postsynaptic-type Kv4.2 and presynaptic-type Kv1.4 IA potassium channels. Eur J Neurosci. 2009; 29(10):1943-50. [PubMed: 19453640]

Arriza JL, Eliasof S, Kavanaugh MP, Amara SG. Excitatory amino acid transporter 5, a retinal glutamate transporter coupled to a chloride conductance. Proc Natl Acad Sci U S A. 1997; 94(8): 4155-60. [PubMed: 9108121]

Audebert M, Charbonnier JB, Boiteux S, Radicella JP. Mitochondrial targeting of human 8oxoguanine DNA glycosylase hOGG1 is impaired by a somatic mutation found in kidney cancer. DNA Repair (Amst). 2002; 1(7):497-505. [PubMed: 12509224]

Ayala-Torres S, Chen Y, Svoboda T, Rosenblatt J, Van Houten B. Analysis of gene-specific DNA damage and repair using quantitative polymerase chain reaction. Methods. 2000; 22(2):135-47. [PubMed: 11020328] 
Ayyildiz M, Coskun S, Yildirim M, Agar E. The effects of ascorbic acid on penicillin-induced epileptiform activity in rats. Epilepsia. 2007; 48(7):1388-95. [PubMed: 17433052]

Bandy B, Davison AJ. Mitochondrial mutations may increase oxidative stress: implications for carcinogenesis and aging? Free Radic Biol Med. 1990; 8(6):523-39. [PubMed: 2193852]

Barros DO, Xavier SM, Barbosa CO, Silva RF, Freitas RL, Maia FD, Oliveira AA, Freitas RM, Takahashi RN. Effects of the vitamin E in catalase activities in hippocampus after status epilepticus induced by pilocarpine in Wistar rats. Neurosci Lett. 2007; 416(3):227-30. [PubMed: 17383094]

Bast A, Haenen GR. Lipoic acid: a multifunctional antioxidant. Biofactors. 2003; 17(1-4):207-13. [PubMed: 12897442]

Beal MF. Mitochondria take center stage in aging and neurodegeneration. Ann Neurol. 2005; 58(4): 495-505. [PubMed: 16178023]

Beckman JS, Koppenol WH. Nitric oxide, superoxide, and peroxynitrite: the good, the bad, and ugly. Am J Physiol. 1996; 271(5 Pt 1):C1424-37. [PubMed: 8944624]

Bellissimo MI, Amado D, Abdalla DS, Ferreira EC, Cavalheiro EA, Naffah-Mazzacoratti MG. Superoxide dismutase, glutathione peroxidase activities and the hydroperoxide concentration are modified in the hippocampus of epileptic rats. Epilepsy Res. 2001; 46(2):121-8. [PubMed: 11463513]

Benz R. Permeation of hydrophilic solutes through mitochondrial outer membranes: review on mitochondrial porins. Biochim Biophys Acta. 1994; 1197(2):167-96. [PubMed: 8031826]

Bidmon HJ, Gorg B, Palomero-Gallagher N, Schleicher A, Haussinger D, Speckmann EJ, Zilles K. Glutamine synthetase becomes nitrated and its activity is reduced during repetitive seizure activity in the pentylentetrazole model of epilepsy. Epilepsia. 2008; 49(10):1733-48. [PubMed: 18479397]

Bidmon HJ, Wu J, Godecke A, Schleicher A, Mayer B, Zilles K. Nitric oxide synthase-expressing neurons are area-specifically distributed within the cerebral cortex of the rat. Neuroscience. 1997; 81(2):321-30. [PubMed: 9300424]

Bikjdaouene L, Escames G, Leon J, Ferrer JM, Khaldy H, Vives F, Acuna-Castroviejo D. Changes in brain amino acids and nitric oxide after melatonin administration in rats with pentylenetetrazoleinduced seizures. J Pineal Res. 2003; 35(1):54-60. [PubMed: 12823614]

Bindoli A. Lipid peroxidation in mitochondria. Free Radic Biol Med. 1988; 5(4):247-61. [PubMed: 3075952]

Bjorneboe A, Nenseter MS, Hagen BF, Bjorneboe GE, Prydz K, Drevon CA. Effect of dietary deficiency and supplementation with all-rac-alpha-tocopherol on hepatic content in rats. J Nutr. 1991; 121(8):1208-13. [PubMed: 1861169]

Bjornsen LP, Eid T, Holmseth S, Danbolt NC, Spencer DD, de Lanerolle NC. Changes in glial glutamate transporters in human epileptogenic hippocampus: inadequate explanation for high extracellular glutamate during seizures. Neurobiol Dis. 2007; 25(2):319-30. [PubMed: 17112731]

Bohr VA, Stevnsner T, de Souza-Pinto NC. Mitochondrial DNA repair of oxidative damage in mammalian cells. Gene. 2002; 286(1):127-34. [PubMed: 11943468]

Bough KJ, Valiyil R, Han FT, Eagles DA. Seizure resistance is dependent upon age and calorie restriction in rats fed a ketogenic diet. Epilepsy Res. 1999; 35(1):21-8. [PubMed: 10232791]

Bough KJ, Wetherington J, Hassel B, Pare JF, Gawryluk JW, Greene JG, Shaw R, Smith Y, Geiger JD, Dingledine RJ. Mitochondrial biogenesis in the anticonvulsant mechanism of the ketogenic diet. Ann Neurol. 2006; 60(2):223-35. [PubMed: 16807920]

Boveris A. Determination of the production of superoxide radicals and hydrogen peroxide in mitochondria. Methods Enzymol. 1984; 105:429-35. [PubMed: 6328196]

Bruce AJ, Baudry M. Oxygen free radicals in rat limbic structures after kainate-induced seizures. Free Radic Biol Med. 1995; 18(6):993-1002. [PubMed: 7628735]

Butterfield DA, Hensley K, Cole P, Subramaniam R, Aksenov M, Aksenova M, Bummer PM, Haley BE, Carney JM. Oxidatively induced structural alteration of glutamine synthetase assessed by analysis of spin label incorporation kinetics: relevance to Alzheimer's disease. J Neurochem. 1997; 68(6):2451-7. [PubMed: 9166739]

Cadenas E, Davies KJ. Mitochondrial free radical generation, oxidative stress, and aging. Free Radic Biol Med. 2000; 29(3-4):222-30. [PubMed: 11035250] 
Carlsson LM, Jonsson J, Edlund T, Marklund SL. Mice lacking extracellular superoxide dismutase are more sensitive to hyperoxia. Proc Natl Acad Sci U S A. 1995; 92(14):6264-8. [PubMed: 7603981]

Castagne V, Gautschi M, Lefevre K, Posada A, Clarke PG. Relationships between neuronal death and the cellular redox status. Focus on the developing nervous system. Prog Neurobiol. 1999; 59(4): 397-423. [PubMed: 10501635]

Cavus I, Kasoff WS, Cassaday MP, Jacob R, Gueorguieva R, Sherwin RS, Krystal JH, Spencer DD, Abi-Saab WM. Extracellular metabolites in the cortex and hippocampus of epileptic patients. Ann Neurol. 2005; 57(2):226-35. [PubMed: 15668975]

Chavko M, Auker CR, McCarron RM. Relationship between protein nitration and oxidation and development of hyperoxic seizures. Nitric Oxide. 2003; 9(1):18-23. [PubMed: 14559428]

Cheng Y, Sun AY. Oxidative mechanisms involved in kainate-induced cytotoxicity in cortical neurons. Neurochem Res. 1994; 19(12):1557-64. [PubMed: 7877729]

Chuang YC, Chang AY, Lin JW, Hsu SP, Chan SH. Mitochondrial dysfunction and ultrastructural damage in the hippocampus during kainic acid-induced status epilepticus in the rat. Epilepsia. 2004; 45(10):1202-9. [PubMed: 15461674]

Cini M, Moretti A. Studies on lipid peroxidation and protein oxidation in the aging brain. Neurobiol Aging. 1995; 16(1):53-7. [PubMed: 7723936]

Cock HR, Tong X, Hargreaves IP, Heales SJ, Clark JB, Patsalos PN, Thom M, Groves M, Schapira AH, Shorvon SD, Walker MC. Mitochondrial dysfunction associated with neuronal death following status epilepticus in rat. Epilepsy Res. 2002; 48(3):157-68. [PubMed: 11904234]

Cohen MR, Ramchand CN, Sailer V, Fernandez M, McAmis W, Sridhara N, Alston C. Detoxification enzymes following intrastriatal kainic acid. Neurochem Res. 1987; 12(5):425-9. [PubMed: 2884584]

Copani A, Hoozemans JJ, Caraci F, Calafiore M, Van Haastert ES, Veerhuis R, Rozemuller AJ, Aronica E, Sortino MA, Nicoletti F. DNA polymerase-beta is expressed early in neurons of Alzheimer's disease brain and is loaded into DNA replication forks in neurons challenged with beta-amyloid. J Neurosci. 2006; 26(43):10949-57. [PubMed: 17065437]

Coppede F, Mancuso M, Lo Gerfo A, Manca ML, Petrozzi L, Migliore L, Siciliano G, Murri L. A Ser326Cys polymorphism in the DNA repair gene hOGG1 is not associated with sporadic Alzheimer's disease. Neurosci Lett. 2007; 414(3):282-5. [PubMed: 17240059]

Costa LG. Signal transduction mechanisms in developmental neurotoxicity: the phosphoinositide pathway. Neurotoxicology. 1994; 15(1):19-27. [PubMed: 8090358]

Costello DJ, Delanty N. Oxidative injury in epilepsy: potential for antioxidant therapy? Expert Rev Neurother. 2004; 4(3):541-53. [PubMed: 15853548]

Coyle JT, Puttfarcken P. Oxidative stress, glutamate, and neurodegenerative disorders. Science. 1993; 262(5134):689-95. [PubMed: 7901908]

Crill WE. Persistent sodium current in mammalian central neurons. Annu Rev Physiol. 1996; 58:349_ 62. [PubMed: 8815799]

Croteau DL, Bohr VA. Repair of oxidative damage to nuclear and mitochondrial DNA in mammalian cells. J Biol Chem. 1997; 272(41):25409-12. [PubMed: 9325246]

Crow JP, Calingasan NY, Chen J, Hill JL, Beal MF. Manganese porphyrin given at symptom onset markedly extends survival of ALS mice. Ann Neurol. 2005; 58(2):258-65. [PubMed: 16049935]

Dabbeni-Sala F, Floreani M, Franceschini D, Skaper SD, Giusti P. Kainic acid induces selective mitochondrial oxidative phosphorylation enzyme dysfunction in cerebellar granule neurons: protective effects of melatonin and GSH ethyl ester. Faseb J. 2001; 15(10):1786-8. [PubMed: 11481230]

Dal-Pizzol F, Klamt F, Vianna MM, Schroder N, Quevedo J, Benfato MS, Moreira JC, Walz R. Lipid peroxidation in hippocampus early and late after status epilepticus induced by pilocarpine or kainic acid in Wistar rats. Neurosci Lett. 2000; 291(3):179-82. [PubMed: 10984636]

Danbolt NC. Glutamate uptake. Prog Neurobiol. 2001; 65(1):1-105. [PubMed: 11369436]

Danbolt NC, Pines G, Kanner BI. Purification and reconstitution of the sodium- and potassiumcoupled glutamate transport glycoprotein from rat brain. Biochemistry. 1990; 29(28):6734-40. [PubMed: 1697765] 
Devi PU, Manocha A, Vohora D. Seizures, antiepileptics, antioxidants and oxidative stress: an insight for researchers. Expert Opin Pharmacother. 2008; 9(18):3169-77. [PubMed: 19040338]

Dexter DT, Carter CJ, Wells FR, Javoy-Agid F, Agid Y, Lees A, Jenner P, Marsden CD. Basal lipid peroxidation in substantia nigra is increased in Parkinson's disease. J Neurochem. 1989; 52(2): 381-9. [PubMed: 2911023]

DiChiara TJ, Reinhart PH. Redox modulation of hslo Ca2+-activated K+ channels. J Neurosci. 1997; 17(13):4942-55. [PubMed: 9185532]

DiMauro S, Schon EA. Mitochondrial respiratory-chain diseases. N Engl J Med. 2003; 348(26):265668. [PubMed: 12826641]

Dizdaroglu M. Chemical determination of free radical-induced damage to DNA. Free Radic Biol Med. 1991; 10(3-4):225-42. [PubMed: 1650738]

Dizdaroglu M. Quantitative determination of oxidative base damage in DNA by stable isotope-dilution mass spectrometry. FEBS Lett. 1993; 315(1):1-6. [PubMed: 8416801]

Duchen MR. Mitochondria and calcium: from cell signalling to cell death. J Physiol. 2000; 529(Pt 1): 57-68. [PubMed: 11080251]

Dugan LL, Sensi SL, Canzoniero LM, Handran SD, Rothman SM, Lin TS, Goldberg MP, Choi DW. Mitochondrial production of reactive oxygen species in cortical neurons following exposure to Nmethyl-D-aspartate. J Neurosci. 1995; 15(10):6377-88. [PubMed: 7472402]

During MJ, Spencer DD. Extracellular hippocampal glutamate and spontaneous seizure in the conscious human brain. Lancet. 1993; 341(8861):1607-10. [PubMed: 8099987]

Dutuit M, Didier-Bazes M, Vergnes M, Mutin M, Conjard A, Akaoka H, Belin MF, Touret M. Specific alteration in the expression of glial fibrillary acidic protein, glutamate dehydrogenase, and glutamine synthetase in rats with genetic absence epilepsy. Glia. 2000; 32(1):15-24. [PubMed: 10975907]

Dutuit M, Touret M, Szymocha R, Nehlig A, Belin MF, Didier-Bazes M. Decreased expression of glutamate transporters in genetic absence epilepsy rats before seizure occurrence. J Neurochem. 2002; 80(6):1029-38. [PubMed: 11953453]

Eid T, Ghosh A, Wang Y, Beckstrom H, Zaveri HP, Lee TS, Lai JC, Malthankar-Phatak GH, de Lanerolle NC. Recurrent seizures and brain pathology after inhibition of glutamine synthetase in the hippocampus in rats. Brain. 2008; 131(Pt 8):2061-70. [PubMed: 18669513]

Eid T, Thomas MJ, Spencer DD, Runden-Pran E, Lai JC, Malthankar GV, Kim JH, Danbolt NC, Ottersen OP, de Lanerolle NC. Loss of glutamine synthetase in the human epileptogenic hippocampus: possible mechanism for raised extracellular glutamate in mesial temporal lobe epilepsy. Lancet. 2004; 363(9402):28-37. [PubMed: 14723991]

Eisenberg D, Gill HS, Pfluegl GM, Rotstein SH. Structure-function relationships of glutamine synthetases. Biochim Biophys Acta. 2000; 1477(1-2):122-45. [PubMed: 10708854]

Elayan IM, Axley MJ, Prasad PV, Ahlers ST, Auker CR. Effect of hyperbaric oxygen treatment on nitric oxide and oxygen free radicals in rat brain. J Neurophysiol. 2000; 83(4):2022-9. [PubMed: 10758112]

Erakovic V, Zupan G, Mrsic J, Simonic A, Varljen J. The influence of nicardipine and ifenprodil on the brain free arachidonic acid level and behavior in hypoxia-exposed rats. Prog Neuropsychopharmacol Biol Psychiatry. 1997; 21(4):633-47. [PubMed: 9194145]

Erakovic V, Zupan G, Varljen J, Laginja J, Simonic A. Lithium plus pilocarpine induced status epilepticus--biochemical changes. Neurosci Res. 2000; 36(2):157-66. [PubMed: 10711813]

Fairman WA, Vandenberg RJ, Arriza JL, Kavanaugh MP, Amara SG. An excitatory amino-acid transporter with properties of a ligand-gated chloride channel. Nature. 1995; 375(6532):599-603. [PubMed: 7791878]

Fighera MR, Royes LF, Furian AF, Oliveira MS, Fiorenza NG, Frussa-Filho R, Petry JC, Coelho RC, Mello CF. GM1 ganglioside prevents seizures, $\mathrm{Na}+\mathrm{K}+-\mathrm{ATPase}$ activity inhibition and oxidative stress induced by glutaric acid and pentylenetetrazole. Neurobiol Dis. 2006; 22(3):611-23. [PubMed: 16516483]

Fishel ML, Seo YR, Smith ML, Kelley MR. Imbalancing the DNA base excision repair pathway in the mitochondria; targeting and overexpressing N-methylpurine DNA glycosylase in mitochondria leads to enhanced cell killing. Cancer Res. 2003; 63(3):608-15. [PubMed: 12566303] 
Fishel ML, Vasko MR, Kelley MR. DNA repair in neurons: so if they don't divide what's to repair? Mutat Res. 2007; 614(1-2):24-36. [PubMed: 16879837]

Floor E, Wetzel MG. Increased protein oxidation in human substantia nigra pars compacta in comparison with basal ganglia and prefrontal cortex measured with an improved dinitrophenylhydrazine assay. J Neurochem. 1998; 70(1):268-75. [PubMed: 9422371]

Folbergrova J, Passonneau JV, Lowry OH, Schulz DW. Glycogen, ammonia and related metabolities in the brain during seizures evoked by methionine sulphoximine. J Neurochem. 1969; 16(2):191203. [PubMed: 5795934]

Folbergrova J, Zhao Q, Katsura K, Siesjo BK. N-tert-butyl-alpha-phenylnitrone improves recovery of brain energy state in rats following transient focal ischemia. Proc Natl Acad Sci U S A. 1995; 92(11):5057-61. [PubMed: 7761448]

Forster MJ, Dubey A, Dawson KM, Stutts WA, Lal H, Sohal RS. Age-related losses of cognitive function and motor skills in mice are associated with oxidative protein damage in the brain. Proc Natl Acad Sci U S A. 1996; 93(10):4765-9. [PubMed: 8643477]

Frantseva MV, Velazquez J.L. Perez, Tsoraklidis G, Mendonca AJ, Adamchik Y, Mills LR, Carlen PL, Burnham MW. Oxidative stress is involved in seizure-induced neurodegeneration in the kindling model of epilepsy. Neuroscience. 2000b; 97(3):431-5. [PubMed: 10828526]

Frantseva MV, Velazquez JL, Hwang PA, Carlen PL. Free radical production correlates with cell death in an in vitro model of epilepsy. Eur J Neurosci. 2000a; 12(4):1431-9. [PubMed: 10762371]

Fraser CM, Sills GJ, Forrest G, Thompson GG, Brodie MJ. Effects of anti-epileptic drugs on glutamine synthetase activity in mouse brain. Br J Pharmacol. 1999; 126(7):1634-8. [PubMed: 10323596]

Freeman BA, Topolosky MK, Crapo JD. Hyperoxia increases oxygen radical production in rat lung homogenates. Arch Biochem Biophys. 1982; 216(2):477-84. [PubMed: 6287935]

Freitas RM, Nascimento VS, Vasconcelos SM, Sousa FC, Viana GS, Fonteles MM. Catalase activity in cerebellum, hippocampus, frontal cortex and striatum after status epilepticus induced by pilocarpine in Wistar rats. Neurosci Lett. 2004; 365(2):102-5. [PubMed: 15245787]

Freitas RM, Vasconcelos SM, Souza FC, Viana GS, Fonteles MM. Oxidative stress in the hippocampus after pilocarpine-induced status epilepticus in Wistar rats. Febs J. 2005; 272(6): 1307-12. [PubMed: 15752349]

Fridovich I. Superoxide radicals, superoxide dismutases and the aerobic lifestyle. Photochem Photobiol. 1978; 28(4-5):733-41. [PubMed: 216032]

Fridovich I. Superoxide radical and superoxide dismutases. Annu Rev Biochem. 1995; 64:97-112. [PubMed: 7574505]

Fridovich I. Superoxide anion radical (O2-.), superoxide dismutases, and related matters. J Biol Chem. 1997; 272(30):18515-7. [PubMed: 9228011]

Frizzo ME, Frizzo JK, Amadio S, Rodrigues JM, Perry ML, Bernardi G, Volonte C. Extracellular adenosine triphosphate induces glutamate transporter-1 expression in hippocampus. Hippocampus. 2007; 17(4):305-15. [PubMed: 17330863]

Gao J, Chi ZF, Liu XW, Shan PY, Wang R. Mitochondrial dysfunction and ultrastructural damage in the hippocampus of pilocarpine-induced epileptic rat. Neurosci Lett. 2007; 411(2):152-7. [PubMed: 17092649]

Gardner PR, Fridovich I. Inactivation-reactivation of aconitase in Escherichia coli. A sensitive measure of superoxide radical. J Biol Chem. 1992; 267(13):8757-63. [PubMed: 1315737]

Garriga-Canut M, Schoenike B, Qazi R, Bergendahl K, Daley TJ, Pfender RM, Morrison JF, Ockuly J, Stafstrom C, Sutula T, Roopra A. 2-Deoxy-D-glucose reduces epilepsy progression by NRSFCtBP-dependent metabolic regulation of chromatin structure. Nat Neurosci. 2006; 9(11):1382-7. [PubMed: 17041593]

Ghijsen WE, da Silva Aresta Belo AI, Zuiderwijk M, da Silva F.H. Lopez. Compensatory change in EAAC1 glutamate transporter in rat hippocampus CA1 region during kindling epileptogenesis. Neurosci Lett. 1999; 276(3):157-60. [PubMed: 10612629]

Gibbs JE, Walker MC, Cock HR. Levetiracetam: antiepileptic properties and protective effects on mitochondrial dysfunction in experimental status epilepticus. Epilepsia. 2006; 47(3):469-78. [PubMed: 16529608] 
Gilberti EA, Trombetta LD. The relationship between stress protein induction and the oxidative defense system in the rat hippocampus following kainic acid administration. Toxicol Lett. 2000; 116(1-2):17-26. [PubMed: 10906418]

Gilly WF, Armstrong CM. Threshold channels--a novel type of sodium channel in squid giant axon. Nature. 1984; 309(5967):448-50. [PubMed: 6328313]

Giulivi C, Boveris A, Cadenas E. Hydroxyl radical generation during mitochondrial electron transfer and the formation of 8-hydroxydesoxyguanosine in mitochondrial DNA. Arch Biochem Biophys. 1995; 316(2):909-16. [PubMed: 7864650]

Gluck MR, Jayatilleke E, Shaw S, Rowan AJ, Haroutunian V. CNS oxidative stress associated with the kainic acid rodent model of experimental epilepsy. Epilepsy Res. 2000; 39(1):63-71. [PubMed: 10690755]

Gong L, Gao TM, Huang H, Tong Z. Redox modulation of large conductance calcium-activated potassium channels in CA1 pyramidal neurons from adult rat hippocampus. Neurosci Lett. 2000; 286(3):191-4. [PubMed: 10832017]

Gorg B, Qvartskhava N, Voss P, Grune T, Haussinger D, Schliess F. Reversible inhibition of mammalian glutamine synthetase by tyrosine nitration. FEBS Lett. 2007; 581(1):84-90. [PubMed: 17174954]

Gorg B, Wettstein M, Metzger S, Schliess F, Haussinger D. LPS-induced tyrosine nitration of hepatic glutamine synthetase. Hepatology. 2005; 42(2):499. [PubMed: 16025504]

Gorter JA, Van Vliet EA, Proper EA, De Graan PN, Ghijsen WE, Da Silva F.H. Lopes, Aronica E. Glutamate transporters alterations in the reorganizing dentate gyrus are associated with progressive seizure activity in chronic epileptic rats. J Comp Neurol. 2002; 442(4):365-77. [PubMed: 11793340]

Greenlund LJ, Deckwerth TL, Johnson EM Jr. Superoxide dismutase delays neuronal apoptosis: a role for reactive oxygen species in programmed neuronal death. Neuron. 1995; 14(2):303-15. [PubMed: 7857640]

Griffiths T, Evans MC, Meldrum BS. Status epilepticus: the reversibility of calcium loading and acute neuronal pathological changes in the rat hippocampus. Neuroscience. 1984; 12(2):557-67. [PubMed: 6462462]

Grollman AP, Moriya M. Mutagenesis by 8-oxoguanine: an enemy within. Trends Genet. 1993; 9(7): 246-9. [PubMed: 8379000]

Gupta RC, Milatovic D, Dettbarn WD. Nitric oxide modulates high-energy phosphates in brain regions of rats intoxicated with diisopropylphosphorofluoridate or carbofuran: prevention by N-tertbutyl-alpha-phenylnitrone or vitamin E. Arch Toxicol. 2001; 75(6):346-56. [PubMed: 11570692]

Gupta YK, Briyal S, Chaudhary G. Protective effect of trans-resveratrol against kainic acid-induced seizures and oxidative stress in rats. Pharmacol Biochem Behav. 2002; 71(1-2):245-9. [PubMed: 11812529]

Gustafsson B, Galvan M, Grafe P, Wigstrom H. A transient outward current in a mammalian central neurone blocked by 4-aminopyridine. Nature. 1982; 299(5880):252-4. [PubMed: 6287290]

Gutteridge JM. Iron and oxygen radicals in brain. Ann Neurol. 1992; 32(Suppl):S16-21. [PubMed: 1510375]

Hahn J, Tse TE, Levitan ES. Long-term K+ channel-mediated dampening of dopamine neuron excitability by the antipsychotic drug haloperidol. J Neurosci. 2003; 23(34):10859-66. [PubMed: 14645479]

Halliwell B, Gutteridge JM. Oxygen free radicals and iron in relation to biology and medicine: some problems and concepts. Arch Biochem Biophys. 1986; 246(2):501-14. [PubMed: 3010861]

Halliwell, B.; Gutteridge, JM. Free radicals in biology and medicine. Oxford University Press; New York: 2007.

Hammarstrom AK, Gage PW. Nitric oxide increases persistent sodium current in rat hippocampal neurons. J Physiol. 1999; 520(Pt 2):451-61. [PubMed: 10523414]

Hammer J, Alvestad S, Osen KK, Skare O, Sonnewald U, Ottersen OP. Expression of glutamine synthetase and glutamate dehydrogenase in the latent phase and chronic phase in the kainate model of temporal lobe epilepsy. Glia. 2008; 56(8):856-68. [PubMed: 18381650] 
Harrison JF, Hollensworth SB, Spitz DR, Copeland WC, Wilson GL, LeDoux SP. Oxidative stressinduced apoptosis in neurons correlates with mitochondrial DNA base excision repair pathway imbalance. Nucleic Acids Res. 2005; 33(14):4660-71. [PubMed: 16107556]

Haugeto O, Ullensvang K, Levy LM, Chaudhry FA, Honore T, Nielsen M, Lehre KP, Danbolt NC. Brain glutamate transporter proteins form homomultimers. J Biol Chem. 1996; 271(44):2771522. [PubMed: 8910364]

Hauptmann N, Grimsby J, Shih JC, Cadenas E. The metabolism of tyramine by monoamine oxidase A/ B causes oxidative damage to mitochondrial DNA. Arch Biochem Biophys. 1996; 335(2):295304. [PubMed: 8914926]

Heinemann U, Buchheim K, Gabriel S, Kann O, Kovacs R, Schuchmann S. Cell death and metabolic activity during epileptiform discharges and status epilepticus in the hippocampus. Prog Brain Res. 2002; 135:197-210. [PubMed: 12143341]

Helms G, Ciumas C, Kyaga S, Savic I. Increased thalamus levels of glutamate and glutamine (Glx) in patients with idiopathic generalised epilepsy. J Neurol Neurosurg Psychiatry. 2006; 77(4):48994. [PubMed: 16543528]

Hertz L. Functional interactions between neurons and astrocytes I. Turnover and metabolism of putative amino acid transmitters. Prog Neurobiol. 1979; 13(3):277-323. [PubMed: 42117]

Hinerfeld D, Traini MD, Weinberger RP, Cochran B, Doctrow SR, Harry J, Melov S. Endogenous mitochondrial oxidative stress: neurodegeneration, proteomic analysis, specific respiratory chain defects, and efficacious antioxidant therapy in superoxide dismutase 2 null mice. J Neurochem. 2004; 88(3):657-67. [PubMed: 14720215]

Hollenbeck PJ, Saxton WM. The axonal transport of mitochondria. J Cell Sci. 2005; 118(Pt 23):54119. [PubMed: 16306220]

Hoogland G, van Oort RJ, Proper EA, Jansen GH, van Rijen PC, van Veelen CW, van Nieuwenhuizen O, Troost D, de Graan PN. Alternative splicing of glutamate transporter EAAT2 RNA in neocortex and hippocampus of temporal lobe epilepsy patients. Epilepsy Res. 2004; 59(2-3):7582. [PubMed: 15246112]

Huang TT, Carlson EJ, Kozy HM, Mantha S, Goodman SI, Ursell PC, Epstein CJ. Genetic modification of prenatal lethality and dilated cardiomyopathy in Mn superoxide dismutase mutant mice. Free Radic Biol Med. 2001; 31(9):1101-10. [PubMed: 11677043]

Hudson EK, Hogue BA, Souza-Pinto NC, Croteau DL, Anson RM, Bohr VA, Hansford RG. Ageassociated change in mitochondrial DNA damage. Free Radic Res. 1998; 29(6):573-9. [PubMed: 10098461]

Imlay JA, Fridovich I. Superoxide production by respiring membranes of Escherichia coli. Free Radic Res Commun. 1991; 12-13(Pt 1):59-66. [PubMed: 1649104]

Ingram EM, Wiseman JW, Tessler S, Emson PC. Reduction of glial glutamate transporters in the parietal cortex and hippocampus of the EL mouse. J Neurochem. 2001; 79(3):564-75. [PubMed: 11701760]

James AM, Murphy MP. How mitochondrial damage affects cell function. J Biomed Sci. 2002; 9(6 Pt 1):475-87. [PubMed: 12372986]

Jamme I, Petit E, Divoux D, Gerbi A, Maixent JM, Nouvelot A. Modulation of mouse cerebral Na ,$+ \mathrm{K}(+)$-ATPase activity by oxygen free radicals. Neuroreport. 1995; 7(1):333-7. [PubMed: 8742483]

Jarrett SG, Liang LP, Hellier JL, Staley KJ, Patel M. Mitochondrial DNA damage and impaired base excision repair during epileptogenesis. Neurobiol Dis. 2008a; 30(1):130-8. [PubMed: 18295498]

Jarrett SG, Milder JB, Liang LP, Patel M. The ketogenic diet increases mitochondrial glutathione levels. J Neurochem. 2008b; 106(3):1044-51. [PubMed: 18466343]

Jenkinson SG. Free radical effects on lung metabolism. Clin Chest Med. 1989; 10(1):37-47. [PubMed: 2539938]

Jensen FE, Applegate CD, Holtzman D, Belin TR, Burchfiel JL. Epileptogenic effect of hypoxia in the immature rodent brain. Ann Neurol. 1991; 29(6):629-37. [PubMed: 1909851]

Jensen FE, Holmes GL, Lombroso CT, Blume HK, Firkusny IR. Age-dependent changes in long-term seizure susceptibility and behavior after hypoxia in rats. Epilepsia. 1992; 33(6):971-80.

[PubMed: 1464280] 
Juhng KN, Kokate TG, Yamaguchi S, Kim BY, Rogowski RS, Blaustein MP, Rogawski MA. Induction of seizures by the potent $\mathrm{K}+$ channel-blocking scorpion venom peptide toxins tityustoxin-K(alpha) and pandinustoxin-K(alpha). Epilepsy Res. 1999; 34(2-3):177-86. [PubMed: 10210033]

Kabuto H, Yokoi I, Ogawa N. Melatonin inhibits iron-induced epileptic discharges in rats by suppressing peroxidation. Epilepsia. 1998; 39(3):237-43. [PubMed: 9578039]

Kanai Y, Hediger MA. Primary structure and functional characterization of a high-affinity glutamate transporter. Nature. 1992; 360(6403):467-71. [PubMed: 1280334]

Kang J, Huguenard JR, Prince DA. Development of BK channels in neocortical pyramidal neurons. J Neurophysiol. 1996; 76(1):188-98. [PubMed: 8836218]

Kim do Y, Davis LM, Sullivan PG, Maalouf M, Simeone TA, van Brederode J, Rho JM. Ketone bodies are protective against oxidative stress in neocortical neurons. J Neurochem. 2007; 101(5): 1316-26. [PubMed: 17403035]

Kisby GE, Milne J, Sweatt C. Evidence of reduced DNA repair in amyotrophic lateral sclerosis brain tissue. Neuroreport. 1997; 8(6):1337-40. [PubMed: 9172131]

Koehler CM. New developments in mitochondrial assembly. Annu Rev Cell Dev Biol. 2004; 20:309_ 35. [PubMed: 15473843]

Komadina KH, Duncan CA, Bryan CL, Jenkinson SG. Protection from hyperbaric oxidant stress by administration of buthionine sulfoximine. J Appl Physiol. 1991; 71(1):352-8. [PubMed: 1680846]

Kosenko E, Llansola M, Montoliu C, Monfort P, Rodrigo R, Hernandez-Viadel M, Erceg S, SanchezPerez AM, Felipo V. Glutamine synthetase activity and glutamine content in brain: modulation by NMDA receptors and nitric oxide. Neurochem Int. 2003; 43(4-5):493-9. [PubMed: 12742096]

Kovacs R, Rabanus A, Otahal J, Patzak A, Kardos J, Albus K, Heinemann U, Kann O. Endogenous nitric oxide is a key promoting factor for initiation of seizure-like events in hippocampal and entorhinal cortex slices. J Neurosci. 2009; 29(26):8565-77. [PubMed: 19571147]

Kucukkaya B, Aker R, Yuksel M, Onat F, Yalcin AS. Low dose MK-801 protects against iron-induced oxidative changes in a rat model of focal epilepsy. Brain Res. 1998; 788(1-2):133-6. [PubMed: 9554983]

Kudin AP, Kudina TA, Seyfried J, Vielhaber S, Beck H, Elger CE, Kunz WS. Seizure-dependent modulation of mitochondrial oxidative phosphorylation in rat hippocampus. Eur J Neurosci. 2002; 15(7):1105-14. [PubMed: 11982622]

Kunz WS, Goussakov IV, Beck H, Elger CE. Altered mitochondrial oxidative phosphorylation in hippocampal slices of kainate-treated rats. Brain Res. 1999; 826(2):236-42. [PubMed: 10224301]

Kunz WS, Kudin AP, Vielhaber S, Blumcke I, Zuschratter W, Schramm J, Beck H, Elger CE. Mitochondrial complex I deficiency in the epileptic focus of patients with temporal lobe epilepsy. Ann Neurol. 2000; 48(5):766-73. [PubMed: 11079540]

Laake JH, Slyngstad TA, Haug FM, Ottersen OP. Glutamine from glial cells is essential for the maintenance of the nerve terminal pool of glutamate: immunogold evidence from hippocampal slice cultures. J Neurochem. 1995; 65(2):871-81. [PubMed: 7616248]

Lafon-Cazal M, Pietri S, Culcasi M, Bockaert J. NMDA-dependent superoxide production and neurotoxicity. Nature. 1993; 364(6437):535-7. [PubMed: 7687749]

Laming PR, Cosby SL, O'Neill JK. Seizures in the Mongolian gerbil are related to a deficiency in cerebral glutamine synthetase. Comp Biochem Physiol C. 1989; 94(2):399-404. [PubMed: 2576778]

Lancaster B, Nicoll RA. Properties of two calcium-activated hyperpolarizations in rat hippocampal neurones. J Physiol. 1987; 389:187-203. [PubMed: 2445972]

Lardot C, Broeckaert F, Lison D, Buchet JP, Lauwerys R. Exogenous catalase may potentiate oxidantmediated lung injury in the female Sprague-Dawley rat. J Toxicol Environ Health. 1996; 47(6): 509-22. [PubMed: 8614020] 
LeDoux SP, Druzhyna NM, Hollensworth SB, Harrison JF, Wilson GL. Mitochondrial DNA repair: a critical player in the response of cells of the CNS to genotoxic insults. Neuroscience. 2007; 145(4):1249-59. [PubMed: 17097236]

Lei SZ, Pan ZH, Aggarwal SK, Chen HS, Hartman J, Sucher NJ, Lipton SA. Effect of nitric oxide production on the redox modulatory site of the NMDA receptor-channel complex. Neuron. 1992; 8(6):1087-99. [PubMed: 1376999]

Leon J, Acuna-Castroviejo D, Sainz RM, Mayo JC, Tan DX, Reiter RJ. Melatonin and mitochondrial function. Life Sci. 2004; 75(7):765-90. [PubMed: 15183071]

Leon J, Macias M, Escames G, Camacho E, Khaldy H, Martin M, Espinosa A, Gallo MA, AcunaCastroviejo D. Structure-related inhibition of calmodulin-dependent neuronal nitric-oxide synthase activity by melatonin and synthetic kynurenines. Mol Pharmacol. 2000; 58(5):967-75. [PubMed: 11040043]

Leonard JV, Schapira AH. Mitochondrial respiratory chain disorders I: mitochondrial DNA defects. Lancet. 2000; 355(9200):299-304. [PubMed: 10675086]

Levy DI, Sucher NJ, Lipton SA. Redox modulation of NMDA receptor-mediated toxicity in mammalian central neurons. Neurosci Lett. 1990; 110(3):291-6. [PubMed: 1970145]

Levy SL, Burnham WM, Bishai A, Hwang PA. The anticonvulsant effects of vitamin E: a further evaluation. Can J Neurol Sci. 1992; 19(2):201-3. [PubMed: 1623446]

Levy SL, Burnham WM, Hwang PA. An evaluation of the anticonvulsant effects of vitamin E. Epilepsy Res. 1990; 6(1):12-7. [PubMed: 2357952]

Li L, Shou Y, Borowitz JL, Isom GE. Reactive oxygen species mediate pyridostigmine-induced neuronal apoptosis: involvement of muscarinic and NMDA receptors. Toxicol Appl Pharmacol. 2001; 177(1):17-25. [PubMed: 11708896]

Li W, Luo Y, Zhang F, Signore AP, Gobbel GT, Simon RP, Chen J. Ischemic preconditioning in the rat brain enhances the repair of endogenous oxidative DNA damage by activating the baseexcision repair pathway. J Cereb Blood Flow Metab. 2006; 26(2):181-98. [PubMed: 16001017]

Li Y, Huang TT, Carlson EJ, Melov S, Ursell PC, Olson JL, Noble LJ, Yoshimura MP, Berger C, Chan PH, Wallace DC, Epstein CJ. Dilated cardiomyopathy and neonatal lethality in mutant mice lacking manganese superoxide dismutase. Nat Genet. 1995; 11(4):376-81. [PubMed: 7493016]

Liang LP, Ho YS, Patel M. Mitochondrial superoxide production in kainate-induced hippocampal damage. Neuroscience. 2000; 101(3):563-70. [PubMed: 11113305]

Liang LP, Jarrett SG, Patel M. Chelation of mitochondrial iron prevents seizure-induced mitochondrial dysfunction and neuronal injury. J Neurosci. 2008; 28(45):11550-6. [PubMed: 18987191]

Liang LP, Patel M. Mitochondrial oxidative stress and increased seizure susceptibility in Sod2(-/+) mice. Free Radic Biol Med. 2004; 36(5):542-54. [PubMed: 14980699]

Liang LP, Patel M. Seizure-induced changes in mitochondrial redox status. Free Radic Biol Med. 2006; 40(2):316-22. [PubMed: 16413413]

Liu H, Moczydlowski E, Haddad GG. O(2) deprivation inhibits $\mathrm{Ca}(2+)$-activated $\mathrm{K}(+)$ channels via cytosolic factors in mice neocortical neurons. J Clin Invest. 1999; 104(5):577-88. [PubMed: 10487772]

Liu P, Qian L, Sung JS, de Souza-Pinto NC, Zheng L, Bogenhagen DF, Bohr VA, Wilson DM 3rd, Shen B, Demple B. Removal of oxidative DNA damage via FEN1-dependent long-patch base excision repair in human cell mitochondria. Mol Cell Biol. 2008; 28(16):4975-87. [PubMed: 18541666]

Lynn S, Huang EJ, Elchuri S, Naeemuddin M, Nishinaka Y, Yodoi J, Ferriero DM, Epstein CJ, Huang TT. Selective neuronal vulnerability and inadequate stress response in superoxide dismutase mutant mice. Free Radic Biol Med. 2005; 38(6):817-28. [PubMed: 15721992]

Ma W, Berg J, Yellen G. Ketogenic diet metabolites reduce firing in central neurons by opening K(ATP) channels. J Neurosci. 2007; 27(14):3618-25. [PubMed: 17409226]

Maalouf M, Sullivan PG, Davis L, Kim DY, Rho JM. Ketones inhibit mitochondrial production of reactive oxygen species production following glutamate excitotoxicity by increasing NADH oxidation. Neuroscience. 2007; 145(1):256-64. [PubMed: 17240074] 
MacGregor DG, Higgins MJ, Jones PA, Maxwell WL, Watson MW, Graham DI, Stone TW. Ascorbate attenuates the systemic kainate-induced neurotoxicity in the rat hippocampus. Brain Res. 1996; 727(1-2):133-44. [PubMed: 8842391]

Mackensen GB, Patel M, Sheng H, Calvi CL, Batinic-Haberle I, Day BJ, Liang LP, Fridovich I, Crapo JD, Pearlstein RD, Warner DS. Neuroprotection from delayed postischemic administration of a metalloporphyrin catalytic antioxidant. J Neurosci. 2001; 21(13):4582-92. [PubMed: 11425886]

Majewska MD, Bell JA, London ED. Regulation of the NMDA receptor by redox phenomena: inhibitory role of ascorbate. Brain Res. 1990; 537(1-2):328-32. [PubMed: 1964838]

Mancini M, Nicholson DW, Roy S, Thornberry NA, Peterson EP, Casciola-Rosen LA, Rosen A. The caspase-3 precursor has a cytosolic and mitochondrial distribution: implications for apoptotic signaling. J Cell Biol. 1998; 140(6):1485-95. [PubMed: 9508780]

Martens JR, Kwak YG, Tamkun MM. Modulation of Kv channel alpha/beta subunit interactions. Trends Cardiovasc Med. 1999; 9(8):253-8. [PubMed: 11094335]

Massieu L, Haces ML, Montiel T, Hernandez-Fonseca K. Acetoacetate protects hippocampal neurons against glutamate-mediated neuronal damage during glycolysis inhibition. Neuroscience. 2003; 120(2):365-78. [PubMed: 12890508]

Mathern GW, Mendoza D, Lozada A, Pretorius JK, Dehnes Y, Danbolt NC, Nelson N, Leite JP, Chimelli L, Born DE, Sakamoto AC, Assirati JA, Fried I, Peacock WJ, Ojemann GA, Adelson PD. Hippocampal GABA and glutamate transporter immunoreactivity in patients with temporal lobe epilepsy. Neurology. 1999; 52(3):453-72. [PubMed: 10025773]

McBean GJ, Doorty KB, Tipton KF, Kollegger H. Alteration in the glial cell metabolism of glutamate by kainate and N-methyl-D-aspartate. Toxicon. 1995; 33(4):569-76. [PubMed: 7570642]

Mecocci P, MacGarvey U, Kaufman AE, Koontz D, Shoffner JM, Wallace DC, Beal MF. Oxidative damage to mitochondrial DNA shows marked age-dependent increases in human brain. Ann Neurol. 1993; 34(4):609-16. [PubMed: 8215249]

Meister A, Anderson ME. Glutathione. Annu Rev Biochem. 1983; 52:711-60. [PubMed: 6137189]

Mejia-Toiber J, Montiel T, Massieu L. D-beta-hydroxybutyrate prevents glutamate-mediated lipoperoxidation and neuronal damage elicited during glycolysis inhibition in vivo. Neurochem Res. 2006; 31(12):1399-408. [PubMed: 17115265]

Meldrum BS, Akbar MT, Chapman AG. Glutamate receptors and transporters in genetic and acquired models of epilepsy. Epilepsy Res. 1999; 36(2-3):189-204. [PubMed: 10515165]

Melov S, Doctrow SR, Schneider JA, Haberson J, Patel M, Coskun PE, Huffman K, Wallace DC, Malfroy B. Lifespan extension and rescue of spongiform encephalopathy in superoxide dismutase 2 nullizygous mice treated with superoxide dismutase-catalase mimetics. J Neurosci. 2001; 21(21):8348-53. [PubMed: 11606622]

Melov S, Schneider JA, Day BJ, Hinerfeld D, Coskun P, Mirra SS, Crapo JD, Wallace DC. A novel neurological phenotype in mice lacking mitochondrial manganese superoxide dismutase. Nat Genet. 1998; 18(2):159-63. [PubMed: 9462746]

Meyerhoff JL, Lee JK, Rittase BW, Tsang AY, Yourick DL. Lipoic acid pretreatment attenuates ferric chloride-induced seizures in the rat. Brain Res. 2004; 1016(2):139-44. [PubMed: 15246849]

Milano J, Day BJ. A catalytic antioxidant metalloporphyrin blocks hydrogen peroxide-induced mitochondrial DNA damage. Nucleic Acids Res. 2000; 28(4):968-73. [PubMed: 10648790]

Milatovic D, Gupta RC, Dettbarn WD. Involvement of nitric oxide in kainic acid-induced excitotoxicity in rat brain. Brain Res. 2002; 957(2):330-7. [PubMed: 12445975]

Milatovic D, Zivin M, Gupta RC, Dettbarn WD. Alterations in cytochrome c oxidase activity and energy metabolites in response to kainic acid-induced status epilepticus. Brain Res. 2001; 912(1): 67-78. [PubMed: 11520494]

Milh M, Becq H, Villeneuve N, Ben-Ari Y, Aniksztejn L. Inhibition of glutamate transporters results in a "suppression-burst" pattern and partial seizures in the newborn rat. Epilepsia. 2007; 48(1): 169-74. [PubMed: 17241224]

Miller HP, Levey AI, Rothstein JD, Tzingounis AV, Conn PJ. Alterations in glutamate transporter protein levels in kindling-induced epilepsy. J Neurochem. 1997; 68(4):1564-70. [PubMed: 9084427] 
Minana MD, Kosenko E, Marcaida G, Hermenegildo C, Montoliu C, Grisolia S, Felipo V. Modulation of glutamine synthesis in cultured astrocytes by nitric oxide. Cell Mol Neurobiol. 1997; 17(4): 433-45. [PubMed: 9262869]

Mohanan PV, Yamamoto HA. Preventive effect of melatonin against brain mitochondria DNA damage, lipid peroxidation and seizures induced by kainic acid. Toxicol Lett. 2002; 129(1-2):99_ 105. [PubMed: 11879979]

Molina-Carballo A, Munoz-Hoyos A, Reiter RJ, Sanchez-Forte M, Moreno-Madrid F, Rufo-Campos M, Molina-Font JA, Acuna-Castroviejo D. Utility of high doses of melatonin as adjunctive anticonvulsant therapy in a child with severe myoclonic epilepsy: two years' experience. J Pineal Res. 1997; 23(2):97-105. [PubMed: 9392448]

Moncada S, Erusalimsky JD. Does nitric oxide modulate mitochondrial energy generation and apoptosis? Nat Rev Mol Cell Biol. 2002; 3(3):214-20. [PubMed: 11994742]

Monyer H, Hartley DM, Choi DW. 21-Aminosteroids attenuate excitotoxic neuronal injury in cortical cell cultures. Neuron. 1990; 5(2):121-6. [PubMed: 2166544]

Mori A, Noda Y, Packer L. The anticonvulsant zonisamide scavenges free radicals. Epilepsy Res. 1998; 30(2):153-8. [PubMed: 9600546]

Mori N, Wada JA, Watanabe M, Kumashiro H. Increased activity of superoxide dismutase in kindled brain and suppression of kindled seizure following intra-amygdaloid injection of superoxide dismutase in rats. Brain Res. 1991; 557(1-2):313-5. [PubMed: 1747763]

Mrsic J, Zupan G, Erakovic V, Simonic A, Varljen J. The influence of nimodipine and MK-801 on the brain free arachidonic acid level and the learning ability in hypoxia-exposed rats. Prog Neuropsychopharmacol Biol Psychiatry. 1997; 21(2):345-58. [PubMed: 9061778]

Mueller SG, Trabesinger AH, Boesiger P, Wieser HG. Brain glutathione levels in patients with epilepsy measured by in vivo (1)H-MRS. Neurology. 2001; 57(8):1422-7. [PubMed: 11673583]

Muller FL, Liu Y, Van Remmen H. Complex III releases superoxide to both sides of the inner mitochondrial membrane. J Biol Chem. 2004; 279(47):49064-73. [PubMed: 15317809]

Muller W, Bittner K. Differential oxidative modulation of voltage-dependent K+ currents in rat hippocampal neurons. J Neurophysiol. 2002; 87(6):2990-5. [PubMed: 12037202]

Nasseh IE, Amado D, Cavalheiro EA, Naffah-Mazzacoratti Mda G, Tengan CH. Investigation of mitochondrial involvement in the experimental model of epilepsy induced by pilocarpine. Epilepsy Res. 2006; 68(3):229-39. [PubMed: 16337777]

Nazarewicz RR, Ziolkowski W, Vaccaro PS, Ghafourifar P. Effect of short-term ketogenic diet on redox status of human blood. Rejuvenation Res. 2007; 10(4):435-40. [PubMed: 17663642]

Neema M, Navarro-Quiroga I, Chechlacz M, Gilliams-Francis K, Liu J, Lamonica K, Lin SL, Naegele JR. DNA damage and nonhomologous end joining in excitotoxicity: neuroprotective role of DNA-PKcs in kainic acid-induced seizures. Hippocampus. 2005; 15(8):1057-71. [PubMed: 16216017]

Nicholls DG. A role for the mitochondrion in the protection of cells against calcium overload? Prog Brain Res. 1985; 63:97-106. [PubMed: 3835584]

Nicholls DG, Ward MW. Mitochondrial membrane potential and neuronal glutamate excitotoxicity: mortality and millivolts. Trends Neurosci. 2000; 23(4):166-74. [PubMed: 10717676]

Noh HS, Hah YS, Nilufar R, Han J, Bong JH, Kang SS, Cho GJ, Choi WS. Acetoacetate protects neuronal cells from oxidative glutamate toxicity. J Neurosci Res. 2006; 83(4):702-9. [PubMed: 16435389]

Nonaka M, Kohmura E, Yamashita T, Shimada S, Tanaka K, Yoshimine T, Tohyama M, Hayakawa T. Increased transcription of glutamate-aspartate transporter (GLAST/GluT-1) mRNA following kainic acid-induced limbic seizure. Brain Res Mol Brain Res. 1998; 55(1):54-60. [PubMed: 9645960]

Ogunmekan AO, Hwang PA. A randomized, double-blind, placebo-controlled, clinical trial of Dalpha-tocopheryl acetate (vitamin E), as add-on therapy, for epilepsy in children. Epilepsia. 1989; 30(1):84-9. [PubMed: 2643513]

Oliver CN, Starke-Reed PE, Stadtman ER, Liu GJ, Carney JM, Floyd RA. Oxidative damage to brain proteins, loss of glutamine synthetase activity, and production of free radicals during ischemia/ 
reperfusion-induced injury to gerbil brain. Proc Natl Acad Sci U S A. 1990; 87(13):5144-7. [PubMed: 1973301]

Ong WY, Hu CY, Hjelle OP, Ottersen OP, Halliwell B. Changes in glutathione in the hippocampus of rats injected with kainate: depletion in neurons and upregulation in glia. Exp Brain Res. 2000; 132(4):510-6. [PubMed: 10912831]

Ong WY, Leong SK, Garey LJ, Reynolds R, Liang AW. An immunocytochemical study of glutamate receptors and glutamine synthetase in the hippocampus of rats injected with kainate. Exp Brain Res. 1996; 109(2):251-67. [PubMed: 8738374]

Otis TS, Wu YC, Trussell LO. Delayed clearance of transmitter and the role of glutamate transporters at synapses with multiple release sites. J Neurosci. 1996; 16(5):1634-44. [PubMed: 8774432]

Packer L, Tritschler HJ, Wessel K. Neuroprotection by the metabolic antioxidant alpha-lipoic acid. Free Radic Biol Med. 1997; 22(1-2):359-78. [PubMed: 8958163]

Packer L, Witt EH, Tritschler HJ. alpha-Lipoic acid as a biological antioxidant. Free Radic Biol Med. 1995; 19(2):227-50. [PubMed: 7649494]

Pan ZH, Bahring R, Grantyn R, Lipton SA. Differential modulation by sulfhydryl redox agents and glutathione of GABA- and glycine-evoked currents in rat retinal ganglion cells. J Neurosci. 1995; 15(2):1384-91. [PubMed: 7869105]

Park MK, Lee SH, Lee SJ, Ho WK, Earm YE. Different modulation of Ca-activated K channels by the intracellular redox potential in pulmonary and ear arterial smooth muscle cells of the rabbit. Pflugers Arch. 1995; 430(3):308-14. [PubMed: 7491253]

Patel M. Superoxide involvement in excitotoxicity: a SOD-mimetic holds promise as a novel neuroprotective agent. Mol Psychiatry. 1996; 1(5):362-3. [PubMed: 9154227]

Patel M. Inhibition of neuronal apoptosis by a metalloporphyrin superoxide dismutase mimic. $\mathbf{J}$ Neurochem. 1998; 71(3):1068-74. [PubMed: 9721731]

Patel M. Mitochondrial dysfunction and oxidative stress: cause and consequence of epileptic seizures. Free Radic Biol Med. 2004; 37(12):1951-62. [PubMed: 15544915]

Patel M, Day BJ. Metalloporphyrin class of therapeutic catalytic antioxidants. Trends Pharmacol Sci. 1999; 20(9):359-64. [PubMed: 10462758]

Patel M, Liang LP, Hou H, Williams BB, Kmiec M, Swartz HM, Fessel JP, Roberts LJ 2nd. Seizureinduced formation of isofurans: novel products of lipid peroxidation whose formation is positively modulated by oxygen tension. J Neurochem. 2008; 104(1):264-70. [PubMed: 17953661]

Patel M, Liang LP, Roberts LJ 2nd. Enhanced hippocampal F2-isoprostane formation following kainate-induced seizures. J Neurochem. 2001; 79(5):1065-9. [PubMed: 11739620]

Patel MN. Oxidative stress, mitochondrial dysfunction, and epilepsy. Free Radic Res. 2002; 36(11): 1139-46. [PubMed: 12592665]

Pellegrini-Giampietro DE, Cherici G, Alesiani M, Carla V, Moroni F. Excitatory amino acid release from rat hippocampal slices as a consequence of free-radical formation. J Neurochem. 1988; 51(6):1960-3. [PubMed: 2903225]

Petroff OA, Errante LD, Rothman DL, Kim JH, Spencer DD. Glutamate-glutamine cycling in the epileptic human hippocampus. Epilepsia. 2002; 43(7):703-10. [PubMed: 12102672]

Pines G, Danbolt NC, Bjoras M, Zhang Y, Bendahan A, Eide L, Koepsell H, Storm-Mathisen J, Seeberg E, Kanner BI. Cloning and expression of a rat brain L-glutamate transporter. Nature. 1992; 360(6403):464-7. [PubMed: 1448170]

Pinz KG, Shibutani S, Bogenhagen DF. Action of mitochondrial DNA polymerase gamma at sites of base loss or oxidative damage. J Biol Chem. 1995; 270(16):9202-6. [PubMed: 7721837]

Proper EA, Hoogland G, Kappen SM, Jansen GH, Rensen MG, Schrama LH, van Veelen CW, van Rijen PC, van Nieuwenhuizen O, Gispen WH, de Graan PN. Distribution of glutamate transporters in the hippocampus of patients with pharmaco-resistant temporal lobe epilepsy. Brain. 2002; 125(Pt 1):32-43. [PubMed: 11834591]

Puttfarcken PS, Getz RL, Coyle JT. Kainic acid-induced lipid peroxidation: protection with butylated hydroxytoluene and U78517F in primary cultures of cerebellar granule cells. Brain Res. 1993; 624(1-2):223-32. [PubMed: 8252395] 
Quach N, Chan T, Lu TA, Schreiber SS, Tan Z. Induction of DNA repair proteins, Ref-1 and XRCC1, in adult rat brain following kainic acid-induced seizures. Brain Res. 2005; 1042(2):236-40. [PubMed: 15854596]

Rauca C, Zerbe R, Jantze H. Formation of free hydroxyl radicals after pentylenetetrazol-induced seizure and kindling. Brain Res. 1999; 847(2):347-51. [PubMed: 10575107]

Reaume AG, Elliott JL, Hoffman EK, Kowall NW, Ferrante RJ, Siwek DF, Wilcox HM, Flood DG, Beal MF, Brown RH Jr. Scott RW, Snider WD. Motor neurons in Cu/Zn superoxide dismutasedeficient mice develop normally but exhibit enhanced cell death after axonal injury. Nat Genet. 1996; 13(1):43-7. [PubMed: 8673102]

Reed DJ, Savage MK. Influence of metabolic inhibitors on mitochondrial permeability transition and glutathione status. Biochim Biophys Acta. 1995; 1271(1):43-50. [PubMed: 7599224]

Reiter RJ. Melatonin, active oxygen species and neurological damage. Drug News Perspect. 1998; 11(5):291-6. [PubMed: 15616649]

Reiter RJ, Tan DX, Poeggeler B, Menendez-Pelaez A, Chen LD, Saarela S. Melatonin as a free radical scavenger: implications for aging and age-related diseases. Ann N Y Acad Sci. 1994; 719:1-12. [PubMed: 8010585]

Reynolds IJ, Rush EA, Aizenman E. Reduction of NMDA receptors with dithiothreitol increases [3H]MK-801 binding and NMDA-induced Ca2+ fluxes. Br J Pharmacol. 1990; 101(1):178-82. [PubMed: 2149291]

Rho JM, Sankar R. The pharmacologic basis of antiepileptic drug action. Epilepsia. 1999; 40(11): 1471-83. [PubMed: 10565572]

Riazanski V, Becker A, Chen J, Sochivko D, Lie A, Wiestler OD, Elger CE, Beck H. Functional and molecular analysis of transient voltage-dependent $\mathrm{K}+$ currents in rat hippocampal granule cells. $\mathrm{J}$ Physiol. 2001; 537(Pt 2):391-406. [PubMed: 11731573]

Richter C, Park JW, Ames BN. Normal oxidative damage to mitochondrial and nuclear DNA is extensive. Proc Natl Acad Sci U S A. 1988; 85(17):6465-7. [PubMed: 3413108]

Roberts LJ, Morrow JD. Measurement of F(2)-isoprostanes as an index of oxidative stress in vivo. Free Radic Biol Med. 2000; 28(4):505-13. [PubMed: 10719231]

Ronne-Engstrom E, Hillered L, Flink R, Spannare B, Ungerstedt U, Carlson H. Intracerebral microdialysis of extracellular amino acids in the human epileptic focus. J Cereb Blood Flow Metab. 1992; 12(5):873-6. [PubMed: 1506452]

Rose C, Felipo V. Limited capacity for ammonia removal by brain in chronic liver failure: potential role of nitric oxide. Metab Brain Dis. 2005; 20(4):275-83. [PubMed: 16382338]

Rothstein JD, Bristol LA, Hosler B, Brown RH Jr. Kuncl RW. Chronic inhibition of superoxide dismutase produces apoptotic death of spinal neurons. Proc Natl Acad Sci U S A. 1994b; 91(10): 4155-9. [PubMed: 7910402]

Rothstein JD, Dykes-Hoberg M, Pardo CA, Bristol LA, Jin L, Kuncl RW, Kanai Y, Hediger MA, Wang Y, Schielke JP, Welty DF. Knockout of glutamate transporters reveals a major role for astroglial transport in excitotoxicity and clearance of glutamate. Neuron. 1996; 16(3):675-86. [PubMed: 8785064]

Rothstein JD, Martin L, Levey AI, Dykes-Hoberg M, Jin L, Wu D, Nash N, Kuncl RW. Localization of neuronal and glial glutamate transporters. Neuron. 1994a; 13(3):713-25. [PubMed: 7917301]

Ruiz-Gomez A, Fernandez-Shaw C, Morato E, Marvizon JC, Vazquez J, Valdivieso F, Mayor F Jr. Sulfhydryl groups modulate the allosteric interaction between glycine binding sites at the inhibitory glycine receptor. J Neurochem. 1991; 56(5):1690-7. [PubMed: 1849551]

Ruppersberg JP, Stocker M, Pongs O, Heinemann SH, Frank R, Koenen M. Regulation of fast inactivation of cloned mammalian IK(A) channels by cysteine oxidation. Nature. 1991; 352(6337):711-4. [PubMed: 1908562]

Ruschenschmidt C, Chen J, Becker A, Riazanski V, Beck H. Functional properties and oxidative modulation of A-type K currents in hippocampal granule cells of control and chronically epileptic rats. Eur J Neurosci. 2006; 23(3):675-85. [PubMed: 16487149]

Sankar R, Holmes GL. Mechanisms of action for the commonly used antiepileptic drugs: relevance to antiepileptic drug-associated neurobehavioral adverse effects. J Child Neurol. 2004; 19(Suppl 1):S6-14. [PubMed: 15526966] 
Santos JH, Meyer JN, Mandavilli BS, Van Houten B. Quantitative PCR-based measurement of nuclear and mitochondrial DNA damage and repair in mammalian cells. Methods Mol Biol. 2006; 314:183-99. [PubMed: 16673882]

Santos LF, Freitas RL, Xavier SM, Saldanha GB, Freitas RM. Neuroprotective actions of vitamin C related to decreased lipid peroxidation and increased catalase activity in adult rats after pilocarpine-induced seizures. Pharmacol Biochem Behav. 2008; 89(1):1-5. [PubMed: 18096215]

Santra S, Gilkerson RW, Davidson M, Schon EA. Ketogenic treatment reduces deleted mitochondrial DNAs in cultured human cells. Ann Neurol. 2004; 56(5):662-9. [PubMed: 15389892]

Schapira AH. Neuroprotection and dopamine agonists. Neurology. 2002; 58(4 Suppl 1):S9-18. [PubMed: 11909981]

Schulz JB, Matthews RT, Jenkins BG, Ferrante RJ, Siwek D, Henshaw DR, Cipolloni PB, Mecocci P, Kowall NW, Rosen BR, et al. Blockade of neuronal nitric oxide synthase protects against excitotoxicity in vivo. J Neurosci. 1995; 15(12):8419-29. [PubMed: 8613773]

Schwartzkroin PA. Mechanisms underlying the anti-epileptic efficacy of the ketogenic diet. Epilepsy Res. 1999; 37(3):171-80. [PubMed: 10584967]

Schwechter EM, J. V, L. V. Correlation between extracellular glucose and seizure susceptibility in adult rats. Ann Neurol. 2002; 53:91-101. [PubMed: 12509852]

Servent D, Menez A, Kessler P. Site-directed disulfide reduction using an affinity reagent: application on the nicotinic acetylcholine receptor. FEBS Lett. 1995; 360(3):261-5. [PubMed: 7883044]

Shaffer SG, O'Neill DH, Thibeault DW. Administration of bovine superoxide dismutase fails to prevent chronic pulmonary sequelae of neonatal oxygen exposure in the rat. J Pediatr. 1987; 110(6):942-6. [PubMed: 3647125]

Shigenaga MK, Park JW, Cundy KC, Gimeno CJ, Ames BN. In vivo oxidative DNA damage: measurement of 8-hydroxy-2'-deoxyguanosine in DNA and urine by high-performance liquid chromatography with electrochemical detection. Methods Enzymol. 1990; 186:521-30. [PubMed: 2233317]

Shimamoto K, Lebrun B, Yasuda-Kamatani Y, Sakaitani M, Shigeri Y, Yumoto N, Nakajima T. DLthreo-beta-benzyloxyaspartate, a potent blocker of excitatory amino acid transporters. Mol Pharmacol. 1998; 53(2):195-201. [PubMed: 9463476]

Shimizu T, Wolfe LS. Arachidonic acid cascade and signal transduction. J Neurochem. 1990; 55(1):115. [PubMed: 2113081]

Sies H. Strategies of antioxidant defense. Eur J Biochem. 1993; 215(2):213-9. [PubMed: 7688300]

Simmet T, Peskar BA. Lipoxygenase products of polyunsaturated fatty acid metabolism in the central nervous system: biosynthesis and putative functions. Pharmacol Res. 1990; 22(6):667-82. [PubMed: 2127458]

Simonson SG, Welty-Wolf KE, Huang YC, Taylor DE, Kantrow SP, Carraway MS, Crapo JD, Piantadosi CA. Aerosolized manganese SOD decreases hyperoxic pulmonary injury in primates. I. Physiology and biochemistry. J Appl Physiol. 1997; 83(2):550-8. [PubMed: 9262452]

Skaper SD, Floreani M, Ceccon M, Facci L, Giusti P. Excitotoxicity, oxidative stress, and the neuroprotective potential of melatonin. Ann N Y Acad Sci. 1999; 890:107-18. [PubMed: 10668417]

Sleven H, Gibbs JE, Heales S, Thom M, Cock HR. Depletion of reduced glutathione precedes inactivation of mitochondrial enzymes following limbic status epilepticus in the rat hippocampus. Neurochem Int. 2006a; 48(2):75-82. [PubMed: 16290321]

Sleven HJ, Gibbs JE, Cock HR. The antioxidant N-acetyl-L-cysteine does not prevent hippocampal glutathione loss or mitochondrial dysfunction associated with status epilepticus. Epilepsy Res. 2006b; 69(2):165-9. [PubMed: 16490347]

Smith CD, Carney JM, Starke-Reed PE, Oliver CN, Stadtman ER, Floyd RA, Markesbery WR. Excess brain protein oxidation and enzyme dysfunction in normal aging and in Alzheimer disease. Proc Natl Acad Sci U S A. 1991; 88(23):10540-3. [PubMed: 1683703]

Sorenson EM, Gallagher JP. The reducing agent dithiothreitol (DTT) does not abolish the inhibitory nicotinic response recorded from rat dorsolateral septal neurons. Neurosci Lett. 1993; 152(1-2): 137-40. [PubMed: 8515866] 
St-Pierre J, Buckingham JA, Roebuck SJ, Brand MD. Topology of superoxide production from different sites in the mitochondrial electron transport chain. J Biol Chem. 2002; 277(47):4478490. [PubMed: 12237311]

Stafstrom CE. Animal models of the ketogenic diet: what have we learned, what can we learn? Epilepsy Res. 1999; 37(3):241-59. [PubMed: 10584974]

Stamler JS, Simon DI, Osborne JA, Mullins ME, Jaraki O, Michel T, Singel DJ, Loscalzo J. Snitrosylation of proteins with nitric oxide: synthesis and characterization of biologically active compounds. Proc Natl Acad Sci U S A. 1992; 89(1):444-8. [PubMed: 1346070]

Steffens M, Huppertz HJ, Zentner J, Chauzit E, Feuerstein TJ. Unchanged glutamine synthetase activity and increased NMDA receptor density in epileptic human neocortex: implications for the pathophysiology of epilepsy. Neurochem Int. 2005; 47(6):379-84. [PubMed: 16095760]

Storck T, Schulte S, Hofmann K, Stoffel W. Structure, expression, and functional analysis of a Na(+)dependent glutamate/aspartate transporter from rat brain. Proc Natl Acad Sci U S A. 1992; 89(22):10955-9. [PubMed: 1279699]

Storm JF. Action potential repolarization and a fast after-hyperpolarization in rat hippocampal pyramidal cells. J Physiol. 1987; 385:733-59. [PubMed: 2443676]

Sucher NJ, Wong LA, Lipton SA. Redox modulation of NMDA receptor-mediated Ca2+ flux in mammalian central neurons. Neuroreport. 1990; 1(1):29-32. [PubMed: 2151794]

Sudha K, Rao AV, Rao A. Oxidative stress and antioxidants in epilepsy. Clin Chim Acta. 2001; 303(1-2):19-24. [PubMed: 11163018]

Sullivan PG, Rabchevsky AG, Waldmeier PC, Springer JE. Mitochondrial permeability transition in CNS trauma: cause or effect of neuronal cell death? J Neurosci Res. 2005; 79(1-2):231-9. [PubMed: 15573402]

Sullivan PG, Rippy NA, Dorenbos K, Concepcion RC, Agarwal AK, Rho JM. The ketogenic diet increases mitochondrial uncoupling protein levels and activity. Ann Neurol. 2004; 55(4):576-80. [PubMed: 15048898]

Susin SA, Lorenzo HK, Zamzami N, Marzo I, Brenner C, Larochette N, Prevost MC, Alzari PM, Kroemer G. Mitochondrial release of caspase-2 and -9 during the apoptotic process. J Exp Med. 1999; 189(2):381-94. [PubMed: 9892620]

Szczesny B, Tann AW, Longley MJ, Copeland WC, Mitra S. Long patch base excision repair in mammalian mitochondrial genomes. J Biol Chem. 2008; 283(39):26349-56. [PubMed: 18635552]

Szegedy L, Sotonyi P, Balogh I. Ultrastructural changes in the rat cerebellar cortex during methionine sulphoximine convulsions. Acta Morphol Acad Sci Hung. 1978; 26(1):11-20. [PubMed: 742416]

Tan DX, Manchester LC, Reiter RJ, Qi W, Kim SJ, El-Sokkary GH. Melatonin protects hippocampal neurons in vivo against kainic acid-induced damage in mice. J Neurosci Res. 1998; 54(3):382-9. [PubMed: 9819143]

Tanaka K, Watase K, Manabe T, Yamada K, Watanabe M, Takahashi K, Iwama H, Nishikawa T, Ichihara N, Kikuchi T, Okuyama S, Kawashima N, Hori S, Takimoto M, Wada K. Epilepsy and exacerbation of brain injury in mice lacking the glutamate transporter GLT-1. Science. 1997; 276(5319):1699-702. [PubMed: 9180080]

Tang L, Reiter RJ, Li ZR, Ortiz GG, Yu BP, Garcia JJ. Melatonin reduces the increase in 8-hydroxydeoxyguanosine levels in the brain and liver of kainic acid-treated rats. Mol Cell Biochem. 1998; 178(1-2):299-303. [PubMed: 9546613]

Tauck DL, Ashbeck GA. Glycine synergistically potentiates the enhancement of LTP induced by a sulfhydryl reducing agent. Brain Res. 1990; 519(1-2):129-32. [PubMed: 1975761]

Taylor CP. Na+ currents that fail to inactivate. Trends Neurosci. 1993; 16(11):455-60. [PubMed: 7507618]

Taylor ER, Hurrell F, Shannon RJ, Lin TK, Hirst J, Murphy MP. Reversible glutathionylation of complex I increases mitochondrial superoxide formation. J Biol Chem. 2003; 278(22):19603-10. [PubMed: 12649289]

Tejada S, Sureda A, Roca C, Gamundi A, Esteban S. Antioxidant response and oxidative damage in brain cortex after high dose of pilocarpine. Brain Res Bull. 2007; 71(4):372-5. [PubMed: 17208654] 
Tessler S, Danbolt NC, Faull RL, Storm-Mathisen J, Emson PC. Expression of the glutamate transporters in human temporal lobe epilepsy. Neuroscience. 1999; 88(4):1083-91. [PubMed: 10336123]

Thibeault DW, Rezaiekhaligh M, Mabry S, Beringer T. Prevention of chronic pulmonary oxygen toxicity in young rats with liposome-encapsulated catalase administered intratracheally. Pediatr Pulmonol. 1991; 11(4):318-27. [PubMed: 1758756]

Thio LL, Wong M, Yamada KA. Ketone bodies do not directly alter excitatory or inhibitory hippocampal synaptic transmission. Neurology. 2000; 54(2):325-31. [PubMed: 10668691]

Thuringer D, Findlay I. Contrasting effects of intracellular redox couples on the regulation of maxi-K channels in isolated myocytes from rabbit pulmonary artery. J Physiol. 1997; 500(Pt 3):583-92. [PubMed: 9161977]

Tokumaru J, Ueda Y, Yokoyama H, Nakajima A, Doi T, Mitsuyama Y, Ohya-Nishiguchi H, Kamada $\mathrm{H}$. In vivo evaluation of hippocampal anti-oxidant ability of zonisamide in rats. Neurochem Res. 2000; 25(8):1107-11. [PubMed: 11055748]

Traynelis SF, Cull-Candy SG. Pharmacological properties and H+ sensitivity of excitatory amino acid receptor channels in rat cerebellar granule neurones. J Physiol. 1991; 433:727-63. [PubMed: 1726797]

Tritschler HJ, Medori R. Mitochondrial DNA alterations as a source of human disorders. Neurology. 1993; 43(2):280-8. [PubMed: 8437690]

Trojnar MK, Malek R, Chroscinska M, Nowak S, Blaszczyk B, Czuczwar SJ. Neuroprotective effects of antiepileptic drugs. Pol J Pharmacol. 2002; 54(6):557-66. [PubMed: 12866709]

Trotti D, Danbolt NC, Volterra A. Glutamate transporters are oxidant-vulnerable: a molecular link between oxidative and excitotoxic neurodegeneration? Trends Pharmacol Sci. 1998; 19(8):32834. [PubMed: 9745361]

Tyler DD. A protective function of superoxide dismutase during respiratory chain activity. Biochim Biophys Acta. 1975; 396(3):335-46. [PubMed: 169898]

Ueda Y, Doi T, Tsuru N, Tokumaru J, Mitsuyama Y. Expression of glutamate transporters and ionotropic glutamate receptors in GLAST knockout mice. Brain Res Mol Brain Res. 2002; 104(2):120-6. [PubMed: 12225864]

Ueda Y, Yokoyama H, Niwa R, Konaka R, Ohya-Nishiguchi H, Kamada H. Generation of lipid radicals in the hippocampal extracellular space during kainic acid-induced seizures in rats. Epilepsy Res. 1997; 26(2):329-33. [PubMed: 9095394]

van der Hel WS, Notenboom RG, Bos IW, van Rijen PC, van Veelen CW, de Graan PN. Reduced glutamine synthetase in hippocampal areas with neuron loss in temporal lobe epilepsy. Neurology. 2005; 64(2):326-33. [PubMed: 15668432]

Van Remmen H, Salvador C, Yang H, Huang TT, Epstein CJ, Richardson A. Characterization of the antioxidant status of the heterozygous manganese superoxide dismutase knockout mouse. Arch Biochem Biophys. 1999; 363(1):91-7. [PubMed: 10049502]

Velioglu SK, Ozmenoglu M, Boz C, Alioglu Z. Status epilepticus after stroke. Stroke. 2001; 32(5): 1169-72. [PubMed: 11340227]

Vielhaber S, Niessen HG, Debska-Vielhaber G, Kudin AP, Wellmer J, Kaufmann J, Schonfeld MA, Fendrich R, Willker W, Leibfritz D, Schramm J, Elger CE, Heinze HJ, Kunz WS. Subfieldspecific loss of hippocampal N-acetyl aspartate in temporal lobe epilepsy. Epilepsia. 2008; 49(1): 40-50. [PubMed: 17822430]

Wang ZW, Nara M, Wang YX, Kotlikoff MI. Redox regulation of large conductance Ca(2+)-activated K+ channels in smooth muscle cells. J Gen Physiol. 1997; 110(1):35-44. [PubMed: 9234169]

Waniewski RA, McFarland D. Intrahippocampal kainic acid reduces glutamine synthetase. Neuroscience. 1990; 34(2):305-10. [PubMed: 1970631]

Wann KT, Richards CD. Properties of single calcium-activated potassium channels of large conductance in rat hippocampal neurons in culture. Eur J Neurosci. 1994; 6(4):607-17. [PubMed: 7517771]

Wispe JR, Warner BB, Clark JC, Dey CR, Neuman J, Glasser SW, Crapo JD, Chang LY, Whitsett JA. Human Mn-superoxide dismutase in pulmonary epithelial cells of transgenic mice confers protection from oxygen injury. J Biol Chem. 1992; 267(33):23937-41. [PubMed: 1385428] 
Woodward JJ, Blair R. Redox modulation of N-methyl-D-aspartate-stimulated neurotransmitter release from rat brain slices. J Neurochem. 1991; 57(6):2059-64. [PubMed: 1682419]

Xavier SM, Barbosa CO, Barros DO, Silva RF, Oliveira AA, Freitas RM. Vitamin C antioxidant effects in hippocampus of adult Wistar rats after seizures and status epilepticus induced by pilocarpine. Neurosci Lett. 2007; 420(1):76-9. [PubMed: 17512118]

Xie Y, Jones GS Jr. Loring RH. Effects of oxidizing and reducing analogs of acetylcholine on neuronal nicotinic receptors. Mol Pharmacol. 1992; 42(2):356-63. [PubMed: 1301068]

$\mathrm{Xu} \mathrm{K}$, Stringer JL. Antioxidants and free radical scavengers do not consistently delay seizure onset in animal models of acute seizures. Epilepsy Behav. 2008; 13(1):77-82. [PubMed: 18396108]

Yakes FM, Van Houten B. Mitochondrial DNA damage is more extensive and persists longer than nuclear DNA damage in human cells following oxidative stress. Proc Natl Acad Sci U S A. 1997; 94(2):514-9. [PubMed: 9012815]

Yamada Y, Nakano K. Increased expression of mitochondrial respiratory enzymes in the brain of activated epilepsy-prone El mice. Brain Res Mol Brain Res. 1999; 73(1-2):186-8. [PubMed: 10581412]

Yamamoto HA, Mohanan PV. Ganglioside GT1B and melatonin inhibit brain mitochondrial DNA damage and seizures induced by kainic acid in mice. Brain Res. 2003; 964(1):100-6. [PubMed: 12573517]

Yildirim M, Marangoz C. Anticonvulsant effects of melatonin on penicillin-induced epileptiform activity in rats. Brain Res. 2006; 1099(1):183-8. [PubMed: 16764841]

Yusa T, Beckman JS, Crapo JD, Freeman BA. Hyperoxia increases H2O2 production by brain in vivo. J Appl Physiol. 1987; 63(1):353-8. [PubMed: 3624137]

Zhang Y, Marcillat O, Giulivi C, Ernster L, Davies KJ. The oxidative inactivation of mitochondrial electron transport chain components and ATPase. J Biol Chem. 1990; 265(27):16330-6. [PubMed: 2168888]

Ziegler DR, Ribeiro LC, Hagenn M, Siqueira IR, Araujo E, Torres IL, Gottfried C, Netto CA, Goncalves CA. Ketogenic diet increases glutathione peroxidase activity in rat hippocampus. Neurochem Res. 2003; 28(12):1793-7. [PubMed: 14649719]

Zoratti M, Szabo I. The mitochondrial permeability transition. Biochim Biophys Acta. 1995; 1241(2): 139-76. [PubMed: 7640294] 


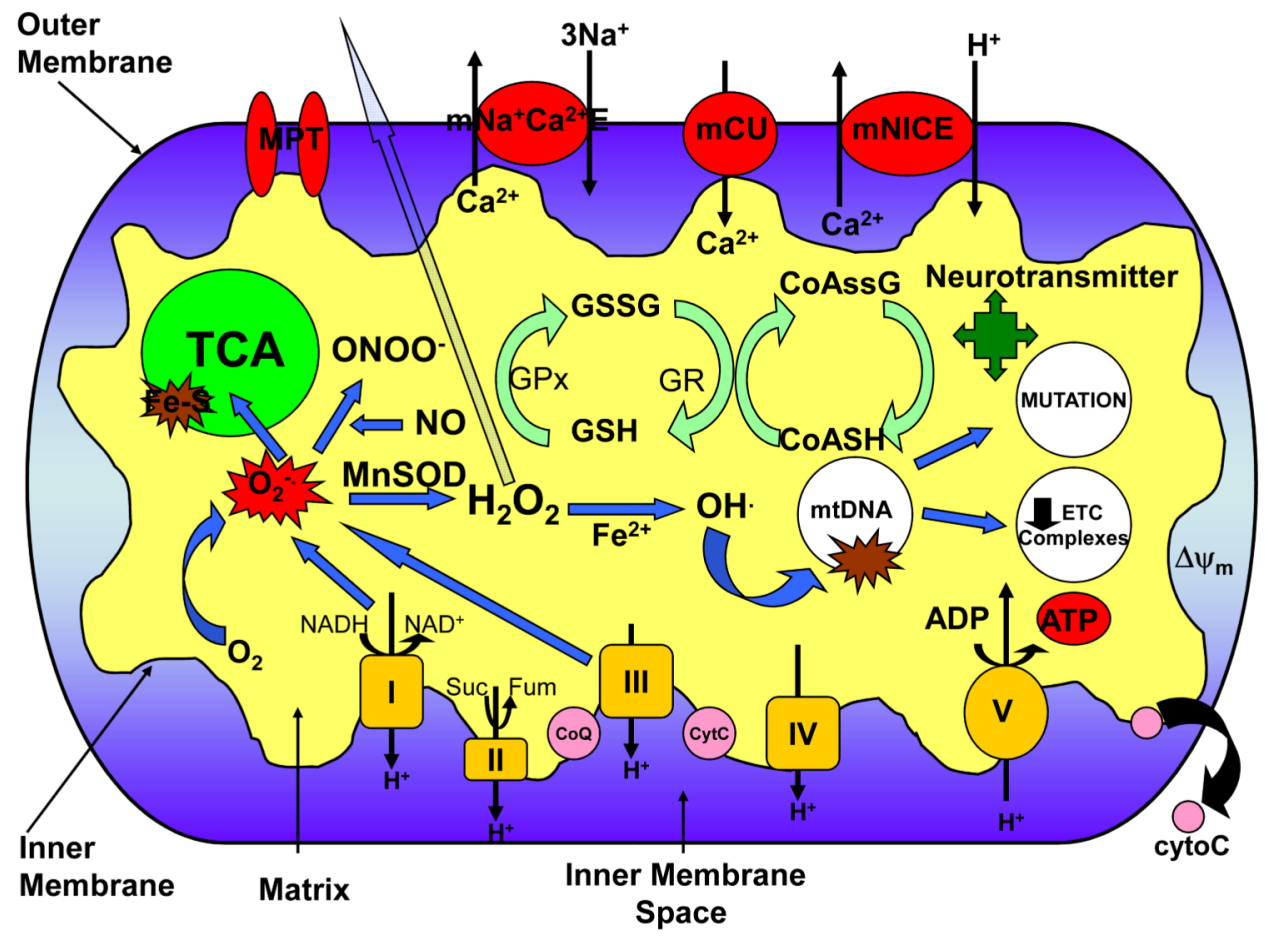

Fig. 1.

Mitochondrial function and neuronal excitability. Various aspects of the mitochondria can lead to impairment of its bioenergetic capacity affecting neuronal excitability, apoptosis, and an increase in seizure susceptibility. $\mathrm{O}_{2} \cdot{ }^{-}$production by complex I and III of the ETC leads to the production of $\mathrm{ONOO}^{-}$in a reaction with $\mathrm{NO}$, and $\mathrm{H}_{2} \mathrm{O}_{2}$ through dismutation by the antioxidant MnSOD (SOD2). $\mathrm{H}_{2} \mathrm{O}_{2}$ is membrane permeable and able to diffuse out of the mitochondria causing widespread oxidative damage. Excessive $\mathrm{O}_{2}{ }^{-}$production also damages Fe-S containing enzymes involved in the TCA cycle such as aconitase. $\mathrm{OH} \cdot$ can be formed from $\mathrm{H}_{2} \mathrm{O}_{2}$ through Fenton chemistry and lead to further oxidative damage of macromolecules such as ETC complexes and mtDNA. Oxidative damage to mtDNA can lead to increased mutation rates and a decrease in ETC subunit expression encoded by the mitochondrial genome. Alterations in the redox status of GSH/GSSG and CoASH/CoASSG can cause an inability to protect against the deleterious effects of ROS. Modification of neurotransmitter biosynthesis within the mitochondria can affect levels of neuronal excitability/inhibition. Oxidative damage to these targets can result in increased neuronal excitability resulting from decreased mitochondrial membrane potential and ATP levels affecting the $\mathrm{Na}^{+} / \mathrm{K}^{+}$ATPase and the release of cyto $\mathrm{C}$ leading to apoptosis. $\mathrm{mNa}^{+} \mathrm{C}^{2+} \mathrm{E}=$ mitochondrial sodium calcium exchanger; $\mathrm{mCU}=$ mitochondrial calcium uniporter; $\mathrm{mNICE}=$ mitochondrial sodium independent calcium exchanger; $\mathrm{MPT}=$ mitochondrial permeability transition pore; $\mathrm{GSH}=$ glutathione; $\mathrm{GSSG}=$ glutathione disulfide; CoASH=coenzyme A; CoASSG=coenzyme A glutathione disulfide; $\mathrm{GR}=$ glutathione reductase; $\mathrm{GPx}=$ glutathione peroxidase; cyto $\mathrm{C}=$ cytochrome $\mathrm{C}$; $\Psi_{\mathrm{m}}=$ mitochondrial membrane potential. 